Comparative Philosophy Volume 11, No. 2 (2020): 1-35

Open Access / ISSN 2151-6014 / www.comparativephilosophy.org

https://doi.org/10.31979/2151-6014(2020).110204

\title{
THE YI-JING COSMIC MODEL: WITH AN APPLICATION OF AN ALTERNATIVE TO NEOLIBERALISM
}

\author{
HARRY DONKERS
}

\begin{abstract}
Based on Yi-Jing we present an elaborated version of the Diagram of the Supreme Polarity that consists of immanent and transcendent processes via the void (Wu-ji), the oneness (Tai-ji), the twofold (Yin and Yang), the fourfold (duograms) and the Five Phases in combination with the eight trigrams (Ba-Gua) to reproduction and the innumerable beings. The duograms are further discussed in a quadrant system with axes derived from pattern li and vital energy qi. The model has similarities with Libbrecht's model of comparative philosophy, but also differences. It is further consistent with the quadrant system of Wilber's integral theory. The trigrams are studied in an octant system, that we derive by adding diagonal axes in the quadrant system, representing competition versus cooperation and renewal versus preservation. This leads to the Ji-Jing cosmic model, which shows a fractal pattern of selfsimilarity of states and stages, with a process of involution, turn and evolution that is propelled by immanent and transcendent flows of energy. There are relationships with various modern approaches, such as Integral Theory, Reflexive Universe and Spiral Dynamics. The model can be used to analyse situations and problems at different levels: cosmos, human world, society, organizations and individuals. I demonstrate that this method, which is based on ancient resources as the Yi-Jing philosophy, through due reflective interpretation can contribute to our understanding and treatment of some currently significant jointly concerned issues. In the application a number of disadvantages of the current neo-liberal system are confronted with some proposed solutions in order to restore the balance between Yin and Yang.
\end{abstract}

Keywords: cosmic YI Ba-Gua, levels, neoliberalism, octant, Supreme Polarity, Yi-Jing

\section{INTRODUCTION}

The Yi-Jing 易經, the Zhou-Yi 周易 plus the Ten-Wings (Shi-Yi 十翼), or the Book of Changes can be seen as the oldest book of wisdom developed at the time of Confucius. In the Yi-Jing the processes in the cosmos and in the human world are presented as the result of the interplay between Yin and Yang. For Confucius, philosophy was a means of learning to become a human being. Yi-Jing and the philosophy of Confucianism have

DONKERS, HARRY: PhD, Independent Scholar, the Netherlands. Email: hdonkers@ziggo.nl 
strongly influenced each other. The moral community and the individual person are inseparable; an individual feels part of a larger whole. The Yi-Jing was, and still is, often consulted by people to gain insight into situations and to adjust their actions accordingly.

Neo-Confucian philosophy has contributed to a better understanding of the Yi-Jing. Zhou Dunyi 周敦願, with his Diagram of Supreme Polarity (Tai-Ji-Tu-Shuo 太極圖說), shifted the focus to a metaphysical discussion about the origin of the universe. Through his view of the universe and how it came about, Zhou Dunyi underlined the copartnership of the universe and the innumerable beings in the constant self-renewal of the universe. Two aspects of the whole and ultimate source of change are represented by two sets of qualities, $l i$ 理 and $q i$ 氣, which are embodied and seen in the dynamic symbolic system of the trigrams and hexagrams. Each thing has two aspects: that what makes it 'how' it is, is $l i$, and 'that' it actually is, is $q i$, to be interpreted as the images and forces of the trigrams respectively.

In an earlier paper Donkers (2019) elaborated on the neo-Confucian interpretation of the Yi-Jing. Based on the Diagram of Supreme Polarity he developed a cosmological-anthropological model with a view to the model of comparative philosophy of Libbrecht, but with a different energy and intentionality concept. He extended a quadrant system of duograms towards an octant system of trigrams that delivered the Yi-Jing cosmic model, with a new Ba-Gua 八卦. In this YI Ba-Gua the sequence of trigrams corresponds to the production cycle of the Five Phases when following the spiral order. This $Y \mathrm{I} B a-G u a$ differs from the $B a-G u a$ of $\mathrm{Fu} \mathrm{Xi}$ 伏羲 by interchanging the pairs of Fire-Water and Lake-Mountain.

In section 2 we consider how the unfolding of the universe, as in the Diagram of Supreme Polarity, is understood in two opposite directions, a process of immanence and transcendence. In this process we show explicitly the connections between Yin 陰 and Yang 陽, the duograms, the Five Phases and the trigrams. In section 3 we discuss the duograms in the quadrant model. Clockwise the duograms follow a cosmic sequence and spiralling we look at a process that shoes the change from Yang to Yin. In the octant model of trigrams in section 4 we demonstrate that the spiral sequence of trigrams follows the sequence of the production cycle. The degrees of freedom of the trigrams in this sequence follow the immanent and transcendent trajectory as in the unfolding of the universe. The vital energy $(q i)$ and the pattern (li) play a central role in the images (states of what the trigram is) and forces (stages of what the trigram does) of the trigrams. The images of the trigrams are displayed in the octants and the forces are depicted as nested circles in this system. In section 5 we pay attention to application of the model at different levels. We show that it is a general model that can be used to analyse situations and problems at different levels, from the cosmos and the human world via society and organizations to the individual level. In section 6 we illustrate the model with an application to the course and problems of neoliberalism and the solutions that platform "2local" proposes. The trigrams facing each other in the octant system are not to be seen as each other's opposites, but just as each other's complements. Finally, section 7 presents a summary. 


\section{THE ELABORATED DIAGRAM OF THE SUPREME POLARITY}

Zhou Dunyi (1017-1073) developed the Diagram of the Supreme Polarity, which describes in a nutshell the evolution of the dynamic and self-generating cosmos (Hon, 2010). In this Diagram of the Supreme Polarity the cosmos, seen as the natural world or universe is unfolded into 2 directions: expanding and tracing back. Donkers (2019) elaborated on this diagram by introducing $l i$ and $q i$ and by incorporating the trigrams that are connected with the Five Phases to fit better with Yi-Jing. Underlying the YiJing philosophy of change is the notion that the cosmos is an organismic process without beginning or end. As a process, the cosmos resembles a great flow in which "all of the parts of the entire cosmos belong to one organic whole" and all the parts "interact as participants in one spontaneously self-generating process" (Tu 1985, 35). In this section we discuss the elaborated Diagram of the Supreme Polarity on the basis of a slightly adjusted overview, see figure 1 .

In origin there was emptiness. The primeval beginning is the $W u-j i$ 無極, drawn as a circle. $W u-j i$ is the primordial, limitless void; it is the unpolarized state before any phenomena arise. $W u-j i$ is undifferentiated, but nonetheless contains the potential for differentiation to arise. In the elaborated Diagram of the Supreme Polarity a second circle (Tai-ji 太極) symbolizes the dynamics of Yin and Yang. Tai-ji is the Supreme Polarity, the arising of something from nothing. The Supreme Polarity in activity generates Yang; yet at the limit of activity it is still. In stillness it generates Yin; yet at the limit of stillness it is active. Activity and stillness alternate; each is the basis of the other (Adler, 2015). As Schöter (2011) explains, there is a bidirectional connection between $W u-j i$ and Tai-ji indicating their interconnected relationship. $W u-j i$ is undifferentiated, but nonetheless contains the potential for differentiation to arise. Zhu $\mathrm{Xi}$ 朱喜 (1130-1200) maintained that all things are brought into being by the union of two universal aspects of reality: $q i$, sometimes translated as vital (or physical, material) force; and $l i$, sometimes translated as rational principle (or law). The Tai-ji concerns polarity as the most fundamental principle of ordering reality, where both the pattern $(l i)$, and the vital energy ( $q i)$ lay the foundation for differentiation. Each thing has two aspects: that which makes it 'how' it is, is $l i$, and 'that' it actually is, is $q i$. The existence of $q i$ implies the existence of $l i$, and vice versa. Both cannot exist without each other. All existence is the result of $l i$ and $q i$ (Bor and Van der Leeuw, 2013). If from the $l i$ of a type of thing, this thing comes to exist, the $l i$ forms the nature of that thing. For example, we can say that the $l i$ of a square is what makes a square square. $Q i$ is an essential part of every living thing. I will go into this further in section 3 where energy and pattern are discussed and in section 4 in relation to the trigrams.

As reported by Wilhelm $(2016,42)$, the Tai-ji simply posits the line, the ridge beam. The line in itself is one. Once differentiation occurs, then the two poles, Yin and Yang, must be identified and characterized. In short the world of opposites makes its entry, represented by a straight and a dashed line: $\boldsymbol{C}$ and $\boldsymbol{-}$ respectively. Yin and Yang arise via Tai-ji, from $W u-j i$. The continuous line symbolizes the heaven /the light, while the broken line symbolizes the earth, the dark. This generates the two primary 
powers, through which a twosome enters the world. This progression lays the foundation for the recursive generation of the Ba-Gua. In the next step of this recursive process of differentiation the new poles of Yang and Yin must be identified and characterized:

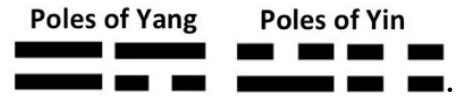

A series of duograms originates. We name this order of duograms the cosmic sequence, indicated by the arrow lines in the upper part of figure 1: Old Yang, Young Yang, Young Yin and Old Yin, respectively. The dashed arrows in the upper part of figure 1 indicate the natural cycle, e.g. Old Yang is associated with summer, Young Yin with autumn, Old Yin with winter and Young Yang with spring. This shoes how the duograms arise via Yin and Yang, Tai-ji and Wu-ji. To show that there is also a cycle in this part of the Diagram we add an arrow between Yin and Yang, indicating that the cycle starts again and on a new level. The two lines of the duograms are placed one above the other, the upper place being the heaven-place and the lower place the earth-place. In trigrams we will see that the man/woman place is shown as the middle place. Now, in the duograms this man/woman place is only imaginary. The duograms will further be discussed in section 3 .

The next step of the recursive process generates the Five Phases ( $W u$-xing 五行 ): wood ( $m u$ 木), fire ( $h u o$ 火), earth ( $t u$ 土), metal (jin 金), water (shui 水) and again wood, which are associated with the trigrams, including Heaven (Qian 乾) and Earth (Kun 坤): Heaven (great metal), Wind (Xun 巽) (wood), Fire ( $i$ 離) (fire), Mountain (Gen 艮) (earth), Lake (Dui 兌) (metal), Water (Kan 坎)(water), Thunder (Zhen 震) (wood) and Earth (great earth). We use the term 'Five Phases' instead of the familiar but erroneous name 'Five Elements' (Mesker, 2002). Also here we add an arrow between Earth and Heaven to show that there is also a cycle in this part of the Diagram. Note that we capitalize the trigrams and lowercase the Five Phases. The trigrams will further be discussed in section 4. In that section we also explain the choice of colours of the trigrams.

Like the first circle, the penultimate and last circles are empty circles. They focus on biological reproduction. The second last circle shows how Yin, the female, and Yang, the male, move. The last circle compares the process by which the innumerable beings are produced by the union of the two sexes. In these two circles the elusive cosmic forces manifest themselves in the creation of the multitude of beings.

The unfolding of the universe can be understood in two opposite directions: an expansion of the Supreme Polarity step-by-step from $W u$-ji to the innumerable beings or the 10,000 Things and a process of tracing the source from the 10,000 things back to $W u-j i$. This corresponds with the degrees of freedom of the trigrams that we discuss further in section 4 . We are talking here about a hierarchical metaphysics. One can descend to the 10,000 Things and ascend to the Supreme Polarity respectively. The immanence and transcendence arrows illustrate this in figure 1. 


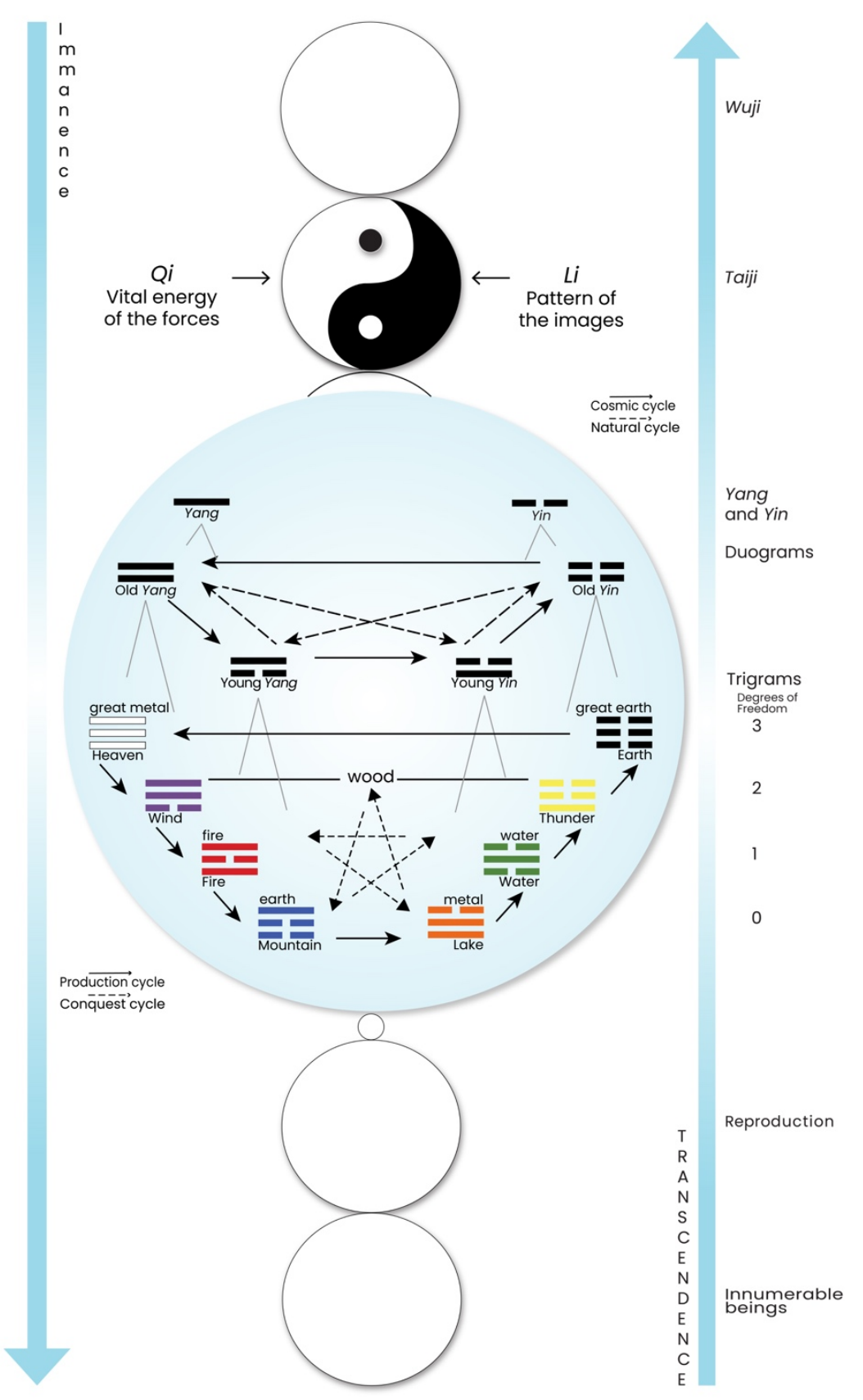

\section{Figure 1. Elaborated Diagram of the Supreme Polarity}

Unfolding the universe into two directions we can also see in the Reflexive Universe of Arthur Young (1999). He developed a fractally-structured hierarchical process theory of the evolution of the universe. His 'Reflexive Universe'-model of Kingdoms (states) and Powers (stages) brings together insights from both the current scientific tradition and the wisdom traditions of the world, including Genesis, Zoroastrianism, Japanese, Greek, Egyptian, and Hindu traditions (Miller, 2006). The states and stages show a process of involution (with decreasing degrees of 
freedom), turning point and evolution (with increasing degrees of freedom). I return to this in section 5, where levels are introduced.

\section{THE QUADRANT MODEL OF DUOGRAMS}

The Diagram of the Supreme Polarity as a whole gives an idea of the cosmic development, or the evolution of the universe. To develop a model we use eastern and western thinking (a.m. Wen 2012, Gao 2015, Van Esch 2017, Wilber 2004 and Libbrecht 2016). The vital energy (qi) and the form aspect or pattern (li) play a central role in this. Libbrecht (2016) developed a model of comparative philosophy that distinguishes between an energetic process and a form aspect (in-form-ation). Every phenomenon is energy $\mathrm{x}$ information, and he uses a coordinate system with these as two respective axes: energy and information. He chooses such a model because it creates a certain order in different philosophical thoughts and theories from various traditions and cultures; it is not just another philosophical theory. It offers a structure of possible, even contradictory, forms of philosophical theory in the East and the West, without a specific philosophical choice. According to Libbrecht it is therefore a "paradigm free" system. I also use such a model as a framework for a comparative philosophy. With Libbrecht (1995a) I see energy and form/pattern as the most universal basic concepts, but with a somewhat different interpretation.

As we saw before in the elaborated Diagram of the Supreme Polarity polarity is the most fundamental principle of ordering reality, where both the pattern ( $l i)$, and the vital energy (qi) lay the foundation for differentiation. Similarly, Libbrecht sees energy and form/pattern as the most universal basic concepts. This coincides with the concepts of $q i$ and $l i$, respectively. $L i$ is labeled as the pattern and structure of the substance, which realizes the substance in its fullest development. $L i$ is not about the substance itself, but about the pattern and structure, which realize the substance. Each thing has two aspects: that which makes it "how" it is, is $l i$, and "that" which it actually is, is qi.

\section{Energy}

In this paper I use a different concept of energy than Libbrecht does. In the concept of Libbrecht, energy in nature is immanent and only in humans it is transcendent. In Libbrecht's concept from the primeval beginning there is bound energy and only with the introduction of the human consciousness free energy arises. This is a peculiar concept of energy. I think Libbrecht overestimates the role of the human species in nature, because man/woman is just part of nature. We think the unfolding of the universe is a cyclical process that starts with free (chaos) energy, inwardly oriented, and goes in an immanent process towards a state of bound energy, after which we find a transcendent process again towards free energy, now outwardly oriented. Furthermore, in the Diagram of the Supreme Polarity the unfolding of the universe is understood in two opposite directions, depicted as immanence and transcendence. This is in line with the thoughts of Arthur Young (1999), who describes the development of the universe in his 'Reflexive Universe'. Arthur Young considers the development from the very beginning until the onset of consciousness in humans. He shows that at first there is a decline in degrees of freedom (involution) and then an increase in degrees of freedom (evolution). The light that has developed after the Big Bang has maximum degrees of freedom and consists entirely of free energy (transcendence). An involution period of binding of energy then breaks, which leads to bound energy: from highly movable particles, via atoms to immobile molecules. The involution process is essentially an immanent process. The energy is turned inwards. From 
there begins an evolutionary period of liberation of energy, through the creation of plants, animals and ultimately humans. The evolution process is a transcendent process, where the energy is turned outwards.

Duograms consist of two lines (straight or closed and dashed or open). The bottom line of the duogram is the earth/body place and the top line is the heaven/mind place. In terms of the change from Yang to Yin, the energy aspect qi ensures that the change from Yang to Yin really occurs and the pattern/form aspect $l i$ indicates how this happens. The unfolding of the Diagram of the Supreme Polarity in the duograms suggests that the energy of qi (that makes a Yang-Yin change happen) is a heavenly inspired development in the cosmos from free energy inside to bound energy and then free energy outside (from Yang-mind to Yin-mind). These are the polarities of the energy axis, shown in figure 2.

\section{Pattern}

'How' the changes from Yang to Yin take place, and thus how things take shape, is the domain of the pattern/form aspect of $l i$ and there are various possibilities for achieving this. The unfolding of the Diagram of the Supreme Polarity in the duograms suggests that the pattern/form aspect is an earthly inspired development in the cosmos with different options (from Yang-body to Yin-body), as in figure 2. This development is directional, rather than directed. I mention this directedness as intentionality, with poles ego (Yang) intentionality and alter (Yin) intentionality. In the cosmos intentionality is controlled by Yang and Yin. In the human world the focus is on the subject (egointentionality) or starting from the subject (alter-intentionality). The polarities of the pattern axis are therefore ego (Yang) intentionality and alter (Yin) intentionality.

My interpretation of intentionality is broader than that of Libbrecht. Libbrecht (1995b) defines intentionality (of the human world) as the whole of spiritual states that focuses on objects or situations in reality and the intentional actions that are driven thereby (consciously or not). In Libbrecht's view the pattern goes from pure knowledge to pure experience. A focus on knowledge corresponds with Plato's dualism, a dichotomy of reality, like a separation between a material body and an immaterial soul. Starting from an "I" is a characteristic feature of Cartesian philosophy. Then intentionality is focused on the self. Libbrecht speaks of ego-intentionality. A focus on experience corresponds to monism. The orientation of intentionality is on the other person. Libbrecht calls this alter-intentionality. From the nature of $l i$ I see in the human world a growth of (intelligent) spirit towards ego-intentionality and a growth of (emotional) mind towards alter-intentionality. In my view intentional processes also take place in the natural world (cosmos). These processes, however, are not induced by human (moral) interaction, but by Yang-Ying dynamics. The question whether there are relationships between the natural order (tian-li 天理) and the moral order (dao-li 道理) is the domain of the linkage between cosmology and ethics, which has been a fundamental assumption of the Confucian worldview since its beginnings (Adler, 2014, 45). This interesting subject, however, is beyond the scope of this paper.

\section{Model}

The polarities of the horizontal energy axis are free energy directed inwards and free energy directed outwards (from Yang-mind to Yin-mind), with bound energy in the 
origin. The polarities of the vertical pattern axis are ego (Yang) intentionality and alter (Yin) intentionality (from Yang-body to Yin-body). The two axes divide the coordinate system into four quadrants, where duograms find their place.

Both in the cosmos and in the human world the polarity of free energy inside oriented corresponds with Yang-mind, which means that the duograms are closed (locked-in as it were) to heaven (the sky), and the polarity of free energy outside oriented corresponds with Yin-mind, which means that the duograms are open to heaven (open to the largeness of the space energy). Both in the cosmos and in the human world the polarity of ego (Yang) intentionality corresponds with Yang-body, which means that the duograms are closed to earth and the polarity of alter ( $\mathrm{Yin}$ ) intentionality corresponds with Yin-body, meaning that the duograms are open to earth. In the human world, when duograms are closed humans are shut to others, or self-centred, while duograms are open humans are approachable to others.

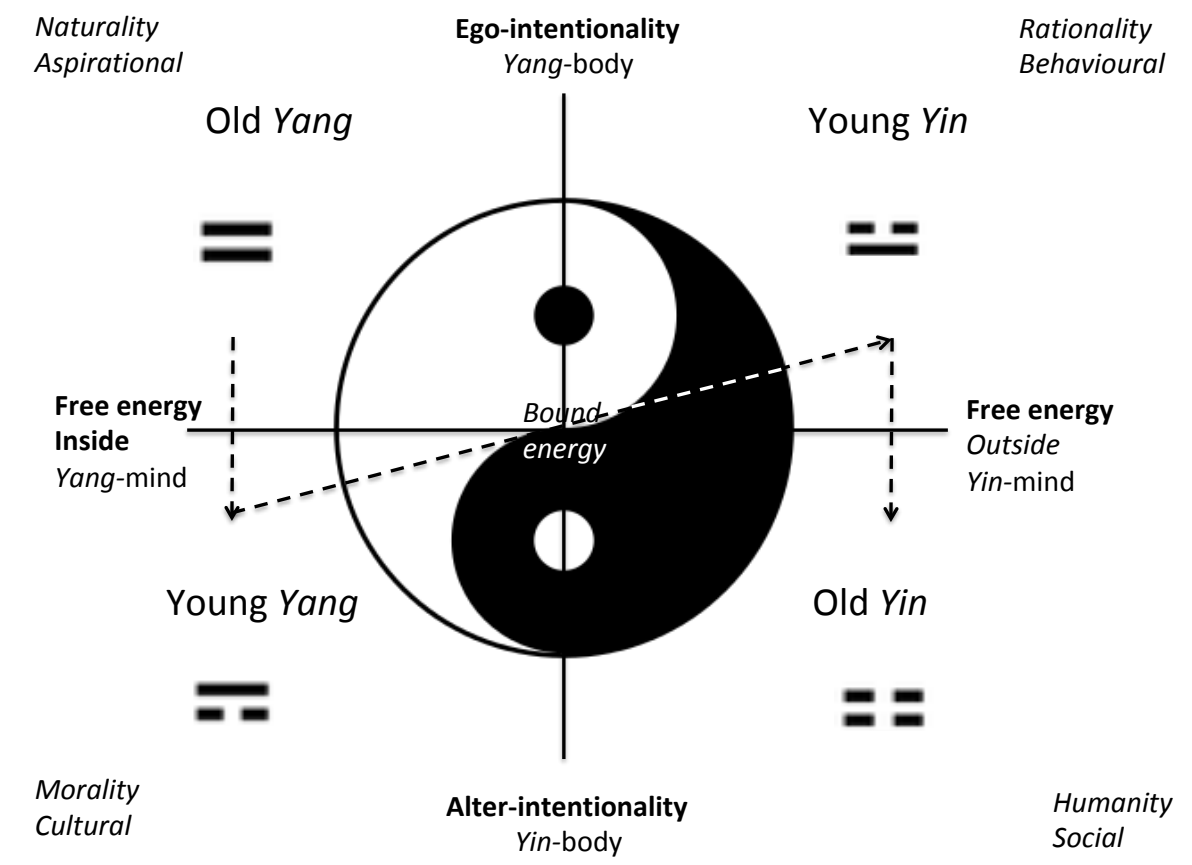

\section{Figure 2. Duograms in the Cosmic ring}

Thus, in the upper-left quadrant the duogram Old Yang is closed to both heaven and earth and in the right-lower quadrant the duogram Old Yin is open to both heaven and earth. In the right-upper quadrant the duogram Young Yin is open to heaven and closed to earth and in the left-lower quadrant de duogram Young Yang is closed to heaven and open to earth. 


\section{Sequences of the duograms}

In figure 2, with monad, we can discover two sequences that we saw before in the Diagram of the Supreme Polarity in figure 1. The clockwise order represents the natural cycle and the spiralling sequence depicts the cosmic cycle.

Natural cycle, clockwise

Looking at the clockwise sequence, we discover the natural sequence that we already saw in figure 1 (dotted line arrows). In figure 2 the interactions between Yin and Yang are mapped into a system of axes according to the classical Chinese representation. In this classical Chinese representation, Young Yang grows into Old Yang, which culminates and turns into Young Yin, which in turn grows into Old Yin, which culminates and turns back into young yang (Boering 2010). Clockwise we see: Old Yang (summer), Young Yin, (autumn), Old Yin (winter) and Young Yang (spring). N.B. In his translation of the Yi-Jing Wilhelm $(2016,271)$ inverts the names for Young Yin and Young Yang.

\section{Cosmic or Process cycle, spiralling}

Following the spiralling path in figure 2 we recognize the process or cosmic sequence of figure 1 (solid line arrow). We now look at the duograms as a process of changing from Yang to Yin. In this process Old Yang first changes to Young Yang, then to Young Yin and finally to Old Yin. Then there will be a change to Yang again, but at another level.

Let's look further to the duograms from the point of view of the human world. Man/woman has not a place in the duograms, but we can give man/woman an imaginary place (human/psyche) in-between heaven and earth. With this in mind we can view the duograms as follows.

\section{a. Old Yang in the left-upper quadrant}

In the upper left quadrant man/woman is closed between heaven and earth. He or she is individual and inwards oriented. He/she is busy with him-/herself, developing insights, making plans, without expressing them. As far as spirituality is concerned, it is oriented towards the own person. It stands for subjective feelings and inner characteristics of individuals. These include personality traits, intelligence and associated values and value systems. What one experiences from within is internal consciousness. It drives his/her intentions, goals and values he/she strives for.

\section{b. Young Yin in the right-upper quadrant}

In the upper right quadrant man/woman is closed to earth and open to heaven. $\mathrm{He} / \mathrm{she}$ is individual and outwards oriented. As far as spirituality is concerned, it is directed at the other/ environment. Human expressions are open-minded and visible. It stands for the "visible appearance" of an individual, such as observable behaviour and skills. These are objective external descriptions. 


\section{c. Old Y in in the right-lower quadrant}

In the lower right quadrant man/woman is open to both heaven and earth. He/she is collective and outwards directed. Human activities are constantly in contact with the earth and with heaven and therefore with the environment. It concerns the 'visible appearance' of the collectivity. This concerns the inter-objective material basis and the external form of collectivity. We can think of the values of the economic base, the (management) systems, the (social) structures of the society.

\section{d. Young Yang in the left-lower quadrant}

In the lower left quadrant, man/woman is closed to heaven but open to earth. He/she is collective inwards oriented. Human activities in this quadrant are earth-oriented and are not disturbed by heaven. The quadrant represents the inter-subjectively shared norms and values of a collective. These are internal opinions/meanings and values that are shared within a community. It concerns the culture, the worldview or the prevailing mutual understanding within a group, organization, sector, region or country.

In the human world, as the comparative model of Libbrecht (2016) does, this quadrant system gives the opportunity to discuss different philosophical traditions in parallel, and contributes to the theory and methodology of comparative philosophy, engaging with similar accounts in literature. Donkers (2019) takes a close look at the philosophical affairs. He distinguishes four perspectives: naturality, rationality, humanity and morality. Libbrecht considers naturality and humanity as one category. Both naturality and humanity are characterized by non-dualism, as in Chinese philosophy, rationality is characterized by dualism as in Western science and in Hinduism, and morality is characterized by monism as in Buddhism.

In the human world we can interpret ego- and alter- intentionality as "I-" and "We-" focused respectively and inwards and outwards directed energy as inside and outside respectively. Therefore, the quadrant system shows similarities with the quadrant system that Wilber (2004) uses in his Integral theory. In his terminology the left-upper quadrant relates to intentional values, the right-upper quadrant to behavioural values, the right-lower quadrant to social values and the left-lower quadrant to cultural values. Since we use the term 'intentional' in a different sense, I name the left-upper quadrant 'aspirational'.

\section{THE OCTANT MODEL OF TRIGRAMS}

In Chinese philosophy, the doubling of the lines in the duograms still did not bring about sufficient differentiation in the worldviews. The next step of the recursive process of differentiation generates the trigrams. A third line is added to the duograms. This is

the human/psyche line that belongs in the middle place. So the man/woman position is introduced in the system in-between heaven/mind in the top line and earth/body in the bottom line.

The elaborated Diagram of the Supreme Polarity in figure 1 shows how the trigrams arise via Wu-ji, Tai-ji, Yin and Yang and the duograms. This is the core of the neo- 
Confucian view of the origin and structure of the universe, which is the entire conceptual system of Wu-ji, Tai-ji, Yin and Yang, duograms and the Five Phases connected with the trigrams. The trigrams consist of all possible combinations of three stacked lines, which can be whole or broken. As a result there are eight trigrams: Heaven, Wind, Fire, Mountain, Lake, Water, Thunder and Earth. In literature we see various other ways to present the trigrams. Schöter (1998) uses a mathematical principle to display the trigrams. Our presentation follows directly from the Diagram of Supreme Polarity.

The trigrams are empowered by $q i$ and take on forms based on $l i$. The basis of the cosmic development is the force $q i$, which supplies the cosmic energy from the free energy of the primeval so that the pattern $l i$ can realize the images. Cheng (2009) discusses $l i$ and $q i$ in the Yi-Jing as two sets of qualities that exist side by side and are never separable. In the context of the symbolism of the eight trigrams he labelled qi as the substance of the qualities such as change, transformation, and movement and li as the substance of the qualities such as patterns, forms, and order. Cheng (2009, 82): "The eight trigrams represent the major forms and patterns of the natural world, which has already been perceived through experience and observation as a well-ordered whole of interrelating and interacting forms." The trigrams: "... constitute the natural referents of the eight trigrams. But the eight trigams do not just represent concrete natural events and forms; they are also principles and qualities of the natural processes and structures." I designate the forms and patterns of the trigrams as "images", and the principles and qualities as "forces". According to Cheng $(2009,82)$ the forces are known as Heaven "strong" (inspiration), Wind "entering" (observing), Fire "travelling in pairs" (thinking), Mountain "stopping" (body), Lake "joy" (feeling), Water "falling in" (soul), Thunder "movement" (spirit), and Earth "soft" (receptive). Our denomination, which is more related to the power qualities of the trigrams, is placed between brackets. Heaven and Earth are the father and mother of the trigrams. This is in line with the Chinese and Islamic mythology in which pivotal inspired messages are sent to man/woman from the chaos of the night. The Heaven-inspired messages lead man/woman to reach a balanced flow of the Five Phases. The different measures of fullness and emptiness, represented by these Five Phases, go back to the receptive Earth.

By introducing man/woman we make a change from duograms to trigrams, from a quadrant system to an octant system, which also has diagonal axes. We first look at the diagonal axes that arise in the octant system, where apart from heaven and earth also man/woman also have a role.

The subjective efforts of the inner world of individuals in the left-upper quadrant are oriented towards developing abilities to meet the requirements of survival, reproduction, achievement, success, etc., i.e. competition. The interobjective and social activities of the outer world of the collective in the right-lower quadrant relate to cooperation, which is opposite to competition. The contrast between the left-upper and the right-lower quadrant is a therefore a sharp contrast between a self-emerging or competing person (closed to heaven and earth) and a person involved in or cooperating with the other (open to heaven and earth). A first diagonal axis compares the 
competition or the struggle in the left-upper quadrant with the cooperative (plus harmony, humanity and meeting) in the right-lower quadrant. The left-upper and the right-lower quadrants are thus divided by a diagonal axis with polarities competition versus cooperation. This axis split the left-upper quadrant into inner competition (Heaven) and individual or ego competition (Fire). In inner competition the efforts are oriented towards survival. In ego-competition the efforts are oriented towards achievement. The right-lower quadrant is split into outer cooperation (Earth) and alter cooperation (Water). Outer cooperation is aimed at building bridges between other social spheres and other times. Alter cooperation is aimed at bonding in collectivities.

The objective efforts of the outer world of individuals in the right-upper quadrant show continuously learning activities and growth, which lead to renewal. The intersubjective and cultural efforts of the inner world of the collective in the left-lower quadrant relate to preservation, which is opposite to renewal. The contrast between the right-upper and the left-lower quadrant is therefore a sharp contradiction between the outwards expressive and innovative man/woman (open to heaven and closed to earth) and the more conservative man/woman set on traditions, rules and norms (closed to heaven and open to earth). The right-upper and the left-lower quadrants are thus divided by a diagonal axis with polarities renewal and preservation. This axis split the rightupper quadrant into ego renewal (Lake) and outer renewal (Thunder). Ego renewal is oriented towards renewal of own ways of thinking, creativity and learning. Outer renewal is outward and open and willing to learn from other people and organizations to innovate. The left-lower quadrant is split into alter preservation (Mountain) and inner preservation (Wind). Alter preservation is oriented towards customs, norms and laws in cultures. Inward-oriented activities in collectivities have interest in preserving social norms. These shared values provide stable surrounding conditions and social control. Inner preservation relates to families, small groups and ethnic cultures, which are usually turned inwards towards their own traditions and histories. These often closedgroups encourage deeper levels of safety and security.

The $B a-G u a$ follows directly from the cosmic ring when we add the human/psycheline to the duograms by putting, from the left to the right, Yang (unbroken line) and Yin (broken line) in every quadrant in the middle place (human line), which is the natural place of the human line, see figure 3 . In this way we place the trigrams in the octant system in a way that the trigrams are closed to heaven in the direction of the free energy inside and open to heaven in the free energy outside direction. The trigrams are closed to earth in the direction of ego-intentionality and open to earth in the alter-intentionality direction. This is a logical extension of the cosmic ring. Of course also in the octant system the polarities of the energy axis, free energy inside and free energy outside correspond with Yang-mind and Yin-mind respectively. And the polarities of pattern axis, ego-intentionality and alter-intentionality, correspond with Yang-body and Yinbody respectively. 


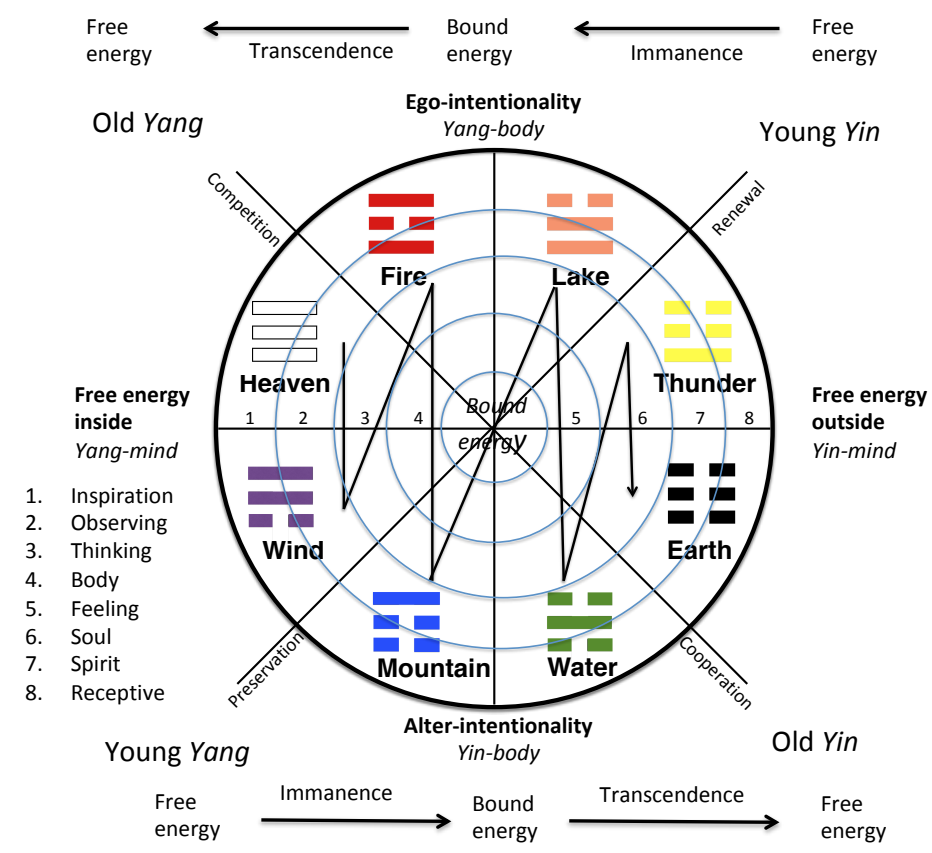

Figure 3. Cosmic YI Ba-Gua

In the octant system of figure 3 we obtain eight ways to look at the cosmologicalanthropological development. This approach leads to a new Ba-Gua with special characteristics (see Donkers 2019). Compared to the Ba-Gua of Fu Xi 伏羲, the trigram pairs of Fire-Water and Lake-Mountain are converted here.

In this octant system we have provided the trigrams with colours. In literature we encounter trigrams in different colours, which often lack a logical basis. We use a simple and logical reasoning here. Yang is always coloured white and Yin black; we leave this as it is. When we then start to give the colour red to Fire in figure 3, and we choose further the colours of the rainbow in a clockwise direction, then the colours of the other trigrams follow naturally. The warm colours (red, orange, yellow) belong to Yang-body and the cold colours (green, blue, purple) belong to Yin-body. A green colour for Water may be a bit surprising, but remember that Water and Fire are contradictory/opposed to each other. From this the choice of green for Water follows as the complement of the warm colour red.

Donkers (2016) used the same quadrant system with accompanying diagonal axes to introduce octants with a view to a connection with Spiral Dynamics, originally developed by Graves (1970) and further popularized by Beck and Cowan (2006). This has led to a new integration between Wilber's Integral Theory and Spiral Dynamics. This new integration differs from "Spiral Dynamics Integral" and also from the approach to integrate these models by Cacioppe and Edwards (2005). Although it is said that the colours of the Spiral Dynamics' categories are chosen randomly, they match - with the exception of the first (Heaven) and the last (Earth) category-the 
colours we have chosen above, on a logical basis, for the trigrams in the relevant octants. Because the basis of this coordinate system lies with our elaboration of the Diagram of the Supreme Polarity and the Integral Theory of Wilber we call this system the cosmic (Yi-Jing Integral) YI Ba-Gua. YI are initials of "Yi-Jing" and "Integral" and $Y i$ 易 means “change" in Chinese. It is therefore nice to also refer to this system as $\mathrm{Yi} B a-G u a$ 易八 卦.

Energy and pattern (li and qi) in the octant system of Yi-Jing

In the Diagram of the Supreme Polarity, the unfolding of the universe is understood in two opposite directions: an immanent process from $W u$-ji, via Tai-ji, and Yin and Yang, the Five elements/trigrams into the innumerable things and a transcendent process all the way back to $W u$-ji. Analogous to the Supreme Polarity we also see in the cosmic development of Yi-Jing first a development from free energy to bound energy and then again a development from bound to free energy. In the immanent process of involution we arrive from the free energy of the transcendent three-dimensional Heaven via Wind, moving in two dimensions (Wind can move in all directions and from top to bottom and vice versa), and Fire, moving in one dimension (fire rises), at the, immanent, Mountain and Lake, both of which have no degrees of freedom (Mountain and Lake cannot change places). With Mountain and Lake we have arrived at the point of bound energy (immanent). From here a transcendent process of evolution takes place. We first come to Water, which can move in one dimension (water falls), then we come to Thunder, which can move in two dimensions (Thunder can move in all directions and from top to bottom and vice versa) and finally we arrive at the three-dimensional Earth. The evolutionary process finally ends up in free energy again (transcendent). See figure 4. In a holistic view, transcendence and immanence are not separate, but two polarizations, which form an integral part of reality. In the immanent process we deal with trigrams that are closed to heaven, while in the transcendent process we deal with trigrams that are open to heaven. Man/woman lives in this field of tension.

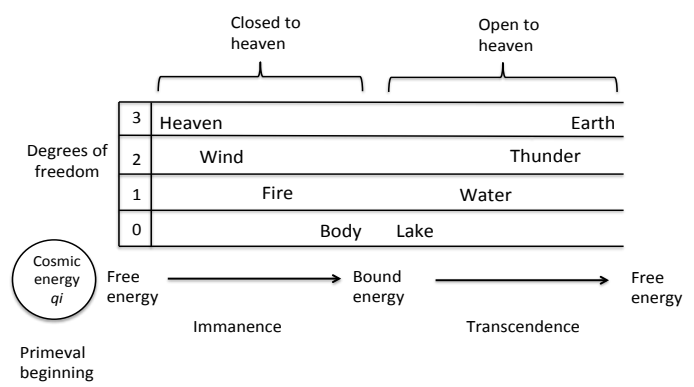

Figure 4. Development of the cosmic energy

We also come across the process of involution, a turn and evolution at Arthur Young's "Reflexive Universe". We also recognize this two-way traffic in modern management 
literature. As an example on an organizational level, Scharmer (2009) treats a change trajectory as a U-process in his 'Theory U'.

The polarities of the pattern axes are ego-intentionality and alter-intentionality. In the direction of ego-intentionality the trigrams are closed to earth and in the direction of alter-intentionality the trigrams are open to earth. See figure 5.

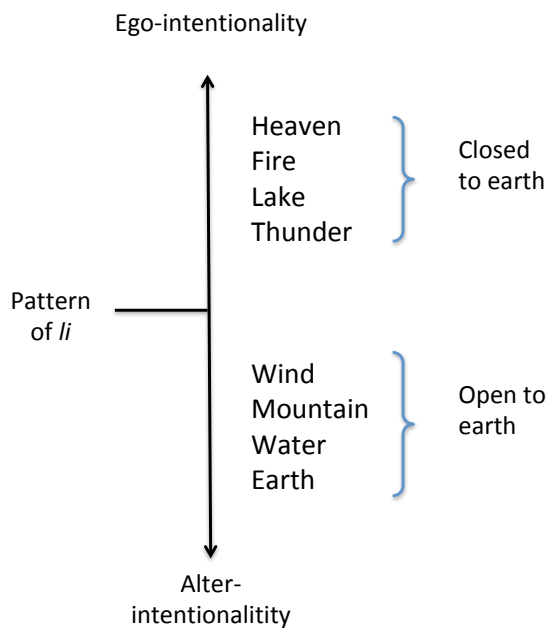

Figure 5. Development of the cosmic pattern

In the West, man/woman is more self-centred. In the East man/woman also gives attention to his/her own inner self, but more to be able to open him-/herself to fellow human beings and the world. 'Letting go' means loosening earthly worries in the West, while in the East it means releasing self-centeredness in order to be able to care for the other person. Van IJssel $(2008,57)$ quotes Heelas et al (2005), who speaks of a "selfin-isolation" in the case of ego-intentionality and a "self-in-relation"' in the case of alterintentionality. The latter case concerns the orientation "the we of me", whereby the self is deeply connected to others and develops "in-relation with". It is a development in which interdependence and independence go together, according to Heelas.

Spiralling sequence fit with the production cycle of the Five Phases

In the Diagram of the Supreme Polarity the Wu-ji, Tai-ji and the interaction of Yang and Yin, give rise to the circulation of the Five Phases: wood, fire, earth, metal, water and again wood, which are connected with the trigrams as we saw in figure 1 . The arrows between wood, fire, earth, metal, water and again wood depict the production cycle of the Five Phases. Heaven is seen as a booster and Earth as a receiver of the production cycle. To show that there is also a cycle including Heaven and Earth, we add an arrow between great earth and great metal, indicating that the cycle starts again and on a new level. The dashed arrows in the form of a star indicate the conquest cycle. 
It shows that in the development process things can go wrong. In the original Diagram the conquest cycle is not depicted.

When we look at the octant system in figure 3 and follow the path spiralling from Yang-mind to Yin-mind we the follow an order with decreasing Yang and increasing Yin. Starting with Heaven, then Wind, Fire, Mountain, Lake, Water, Thunder and finally Earth, we get the trigram sequence corresponding to the production cycle of the Five Phases. See figure 6.

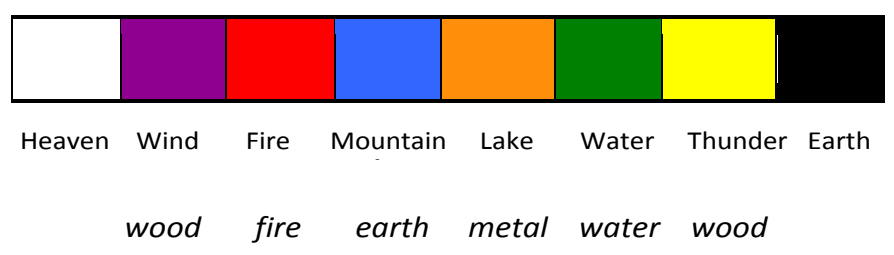

Figure 6. Spiralling sequence of trigrams following the order of the production cycle

The spiral sequence also shows a development process. Cool tones alternate with warm. Heaven indicates a clear path with bright initiatives. The Wind provides some reflection. Fire promises action. It ensures a breakthrough. The Mountain collects information, analyses and searches for a balance. The Lake makes great plans to flourish so that success can be achieved. Water brings people together. The Thunder brings strong energy with it in a chaotic quest. The Earth stimulates collective peace and progress.

\section{Images and forces}

With respect to the trigrams two sets of qualities are at stake. Apart from the qualities such as forms and pattern, labelled as $l i$, which relate to the images of the trigrams, we have qualities such as change, transformation and movement, labelled as $q i$, which relate to the forces of the trigrams. The forces of the trigrams provide the energy to realize the images. For a further description of the images and forces of trigrams see Donkers (2019). These are steps in a cyclical process. The energy forces in the cosmos were also studied by Maturana and Varela (1989) and applied to living systems. We think that similar forces work in the cosmos, where man has found a place. Both nature and man can disturb the harmony. A big difference is that people are aware of this with their consciousness.

Events in the cosmos or in the human world are the result of the interplay between polarities, like Yang and Yin, where opposite forces play an important role. These opposite forces of the cosmos are hidden metaphorically in nested circles of the 
contrasted trigrams with the same degrees of freedom. Therefore we can incorporate the working of the energy forces into the octant system as nested circles in figure 3. This coordinate system not only shows the images (what the trigram is), but also the forces (what the trigram does). In doing so, we must remember that the forces, not only influence their own trigram, but also affect the other trigrams.

The images and forces of the trigrams can be seen as milestones or 'states' that are achieved by forces working in several steps or "stages" of a development process. We can compare the images and forces with the "Kingdoms" and "Powers" of the Reflexive Universe of Young (1999), the "quadrants" and "levels of development" of Wilber, the "Life conditions" and the "Mind coping capacities" of Graves (1970)/Beck and Cowan (2006). It always involves the milestones and steps in a "double helix" development process. The combination of the 8 states and 8 stages is represented in a matrix of 64 elements, which provides even greater differentiation. The most famous matrix is the matrix of hexagrams of the Yi-Jing, which is described in detail in the Book of Changes, see for example Wilhelm (2016). The images of the trigrams, as basic trigrams, are combined with the forces of the trigrams, as top trigrams, as in Donkers (2019), so that 64 cases are obtained, all consisting of 6 lines. The lines are thought variable. When a line changes, the character of a hexagram changes into the character of another hexagram. This combination is possible at all levels, see the next section. Apart from the cosmic level (Yi-Jing), we find some elaborations in the literature at the level of the organization, such as by Hamaker-Zondag (1989), but not at other levels, not even in the extensive literature about Spiral Dynamics. There is still a lot of work to be done here.

\section{LEVELS}

The model we have developed in this paper is based on the Yi-Jing or Book of Changes (Zhou-Yi plus Ten-Wings), which is an ancient Chinese book of wisdom and divination. It is the oldest of the Chinese Classics, an influential text read throughout the world, providing inspiration to the worlds of religion, philosophy, literature, and art. Underlying the Yi-Jing philosophy of change is the notion that the cosmos is an organismic process without beginning or end. Our model is based on the general observation that events in the cosmos show a fractal pattern of self-similarity of states and stages, of which the trigrams and hexagrams are proof. We have discovered that these patterns show a spiralling or alternating process sequence between an individual and a community focus. We see involution, turn and evolution in the development of the process, which is propelled by immanent and transcendent flows of energy. To deal in a practical sense with this "whole", I identify five different levels: individuals, organizations, societies, human world and cosmos. However, since participants interact not only within levels but also between levels, there is no sharp distinction between the levels. Moreover, if the flow in one level is obstructed, that will manifest itself not only in certain impediments in that level, but it will also manifest itself in other levels that get out of balance. As an example I mention individual humans as basic constituents of organizations and societies. So, when an individual has to deal with role confusion that 
result in an identity crisis this will also cause dysfunction in organizations, wider societies and so forth. Figure 7 gives an overview of the levels of the comparative octant model.

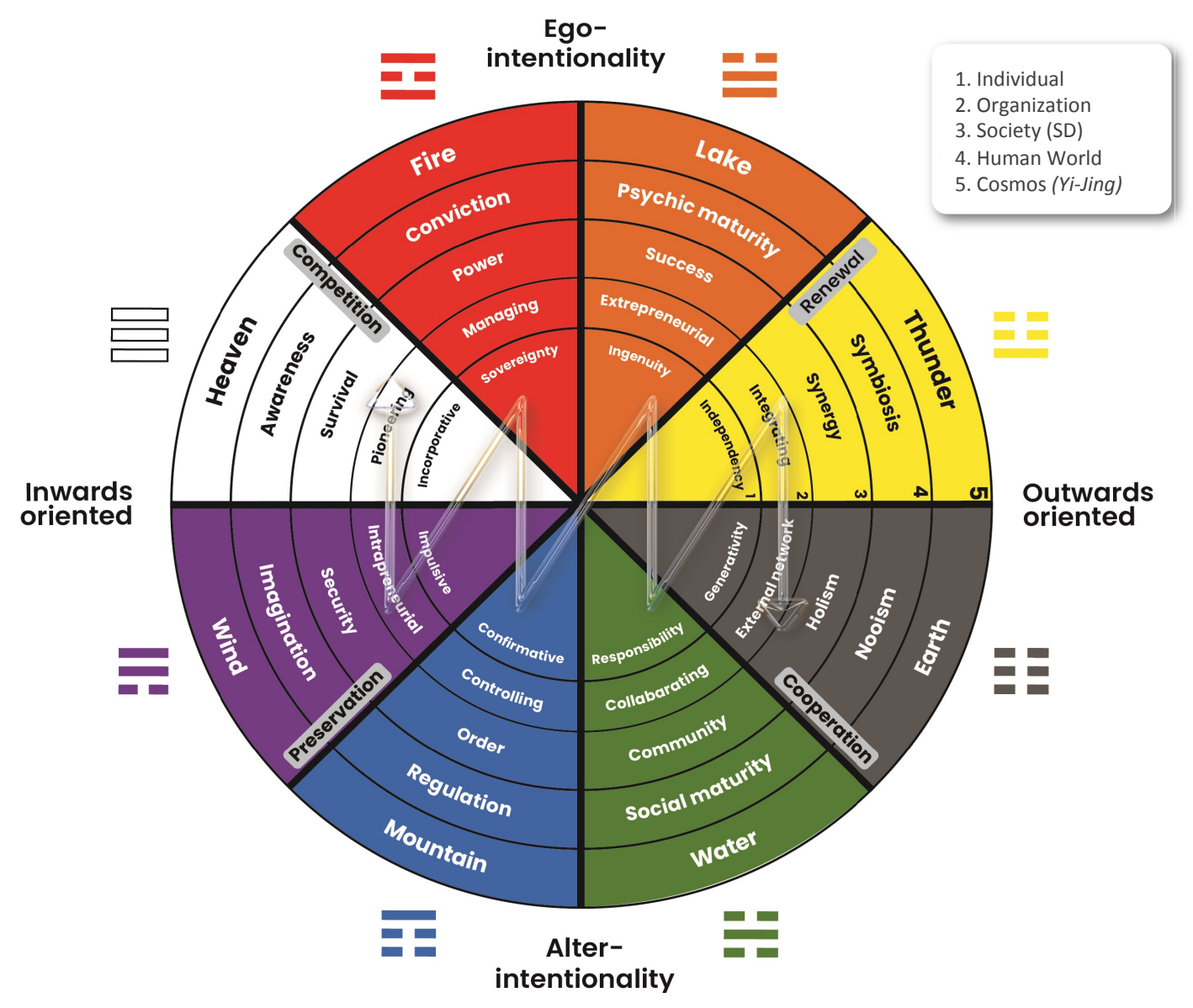

Figure 7. States of the levels in the comparative octant model

In figure 7 the only the "states" of the various levels are presented in the octants of the comparative octant model. Figure 8 show a complete picture of the states and stages at the various levels.

\section{Cosmos}

The Diagram of the Supreme Polarity describes the evolution of the dynamic and selfgenerating cosmos (or universe as a whole) and shows how the cosmos is unfolded. The elaborated Diagram of the Supreme Polarity in figure 1 shows how the trigrams, connected to the Five Phases, arise via Wu-ji, Tai-ji, Yin and Yang and the duograms. As we saw in section 4, in the context of the symbolism of the eight trigrams there are two sets of qualities: change, transformation, and movement, designated as "images" of the trigrams on the one side, and patterns, forms, and order, labelled as "forces" on 
the other side. As we saw before the images and forces of the trigrams can be seen as milestones or 'states' that are achieved by forces working in several steps or "stages" of a development process.

\section{Human World}

Human world studies are rare. For a description of the evolution of the human world, I consult studies of the cosmos. In the west, Alexander von Humboldt (1769-1859) was a research pioneer on the development of the cosmos (Walls, 2009). Also Spier (2005) and Chaisson (2005) involved themselves in this. According to Chaisson (2005) there have been 8 ages of epochs of the cosmos: Particulate, Galactic, Stellar, Planetary, Chemical, Biological, Cultural, and Future. Young (1999) distinguished 7 states (stages) of the cosmos or universe: Light (Potential), Nuclear particles (Form), Atomic (Identity), Molecular (Formed substance) as turning point, Plants (Growth), Animal (Animation), Anthropotheos (Dominion). The model of Arthur Young describes a fractal development process from the primeval (Light/Potential), to the emergence of consciousness in men/women (Anthropotheos/Dominion) in seven steps. I now assume that the development of consciousness in the Human World follows a similar fractal pattern on a lower level scale, from the very beginning (Awareness/Inherent natural) to the very future, when it may develop into collective consciousness of men/women or some kind of future as indicated by an omega point by Teilhard de Chardin (Nooism/Terminal). Where Young distinguished seven steps I differentiate between eight steps to get a close correspondence with the eight trigrams. The states or domains in this path start with Awareness. Then an involution trajectory follows from Imagination via Conviction to the turning point that now consists of Regulation and Psychic maturity, and an evolutionary route via Social maturity and Symbiosis to Nooism. The stages that we discover here are respectively: Inherent natural, Inherent human, Meaning, (Re)production, Self-organization, Growth, Mobility and Terminal.

\section{Society}

Graves (1970) developed a model of interaction between external disorders and internal neurological systems to solve existential problems and deal with the world. This is a double helix theory where "Levels of Psychological Existence" as "Life conditions" interact with the neurobiological 'Coping systems' activated in the mind/brain. Beck and Cowan (2006) developed this model further and popularized it in Spiral Dynamics to a more general use. It became a growth model that uses worldview analysis to evaluate how and why events occur in social situations. The value systems of Spiral Dynamics structure the political forms and the worldviews of persons, corporate cultures and entire civilizations. In practice it is most commonly used for analysing social events. The distinguished states (stages) are: Survival (Instinctive), Security (Animistic), Power (Egocentric), Order (Absolutistic), Success (Multiplistic), Community (Relativistic), Synergy (Systemic) and Holism (Holistic). There is a close connection between the value systems of Spiral Dynamics and the trigrams, see Donkers (2016, 2019). 


\section{Organization}

There is a vast literature on organizational development. We mention but a few: the Rose of Leary (1957), the Leadership Circumflex (Redeker et al, 2014), the model of Quinn (Quinn and Rohrbaugh, 1983), the Management I Tjing (Hamaker-Zondag, 1989), the development steps of Keuning and Eppink (2004), Cacioppe and Edwards (2005). The subjects range from traditional, modern, postmodern and future organizations. Cacioppe and Edwards (2005) compared the management point of view with Spiral Dynamics. They presented management aspects in relation to the eight value systems of Spiral Dynamics and Wilber's quadrants. With regard to the organizational level I observe a close connection between organization types and styles and trigrams. Drawing on the literature mentioned I distinguish as states (stages): Pioneering (Intuitive), Intrapreneurial (Coaching), Business managing (Prestigious), Controlling (Procedural), Entrepreneurial (Inspirational), Collaborating (Engaging), Integrating (Flexibility) and External networking (Idealistic).

\section{Individual}

Freud (1856-1939) considered that personality of individuals is formed mainly in the first 6 years, through unconscious processes under the influence of one's parents, and that personality formation is irreversible. Jung (1931) believed that there are only four stages of life: athlete, warrior, statement and spirit. Erikson, a student of Freud, differed from Freud in giving more emphasis to social and cultural forces of development. Erikson (1963) conceived personality formation to be more malleable and to continue throughout life, to be influenced by friends, the family and society. His theory presents a progression through eight psychosocial stages that with some adaptations fit in the comparative octant model. At each stage there is a crisis and its resolution leads to development of a virtue. The developmental model of Kegan (1982) rests on the assumption that the self forms its successive self-other balances in alternate favouring's of one or the other side of an inclusion-independence polarity. The six stages of Kegan correspond to the comparative octant model with the following adaptations. I take the holding and confirming function of his Imperial stage as a separate - inclusion - stage, and I see the possible loss of identity and independence in his Interpersonal stage as a separate - independence - stage. Drawing on the literature mentioned I distinguish as states (stages): Incorporative (Sensing), Impulsive (Exploring), Sovereign (Selfsufficiency), Confirmative (Restraining), Ingenuity (Struggling), Responsibility (Inquiring), Independency (Rediscovering) and Generativity (Contemplating).

In figure 8 apart from the states also the stages at the different levels are presented. We follow the spiral path of figure 3 . 


I. Individual

Figure 8, States and stages of the levels of the comparative octant model

In this paper I only present a brief description of the states and stages at the different levels. Below I combine the different levels with the appropriate states and stages. Information with respect to Society is taken from: http://spiraldynamics.org/aboutoverview/.

\begin{tabular}{|l|l|l|}
\hline Level & States & Stages \\
\hline Heaven 乾 & \multicolumn{2}{|l|}{} \\
\hline Cosmos & $\begin{array}{l}\text { Heaven: creativity, unlimited } \\
\text { possibilities, new ideas and impulses } \\
\text { apply, movement, light, brightness, sun } \\
\text { and action. }\end{array}$ & $\begin{array}{l}\text { Inspiration: the beginning of Chinese } \\
\text { thinking about man/woman, society and } \\
\text { cosmos, the awakening of the creative } \\
\text { power, with which ideas and initiatives } \\
\text { come into being. }\end{array}$ \\
\hline $\begin{array}{l}\text { Human } \\
\text { World }\end{array}$ & $\begin{array}{l}\text { Consciousness: the mental and spiritual } \\
\text { activity. }\end{array}$ & $\begin{array}{l}\text { Inherent natural: living in harmony with } \\
\text { nature and with the spirit of the times, } \\
\text { basic, ecosystems, resilience, } \\
\text { interactive. }\end{array}$ \\
\hline Society & $\begin{array}{l}\text { Survival: state of nature and biological } \\
\text { urges and drives, physical senses dictate } \\
\text { the state of being. }\end{array}$ & $\begin{array}{l}\text { Instinctive: natural instincts and reflexes } \\
\text { direct, automatic existence. }\end{array}$ \\
\hline \multicolumn{2}{|l}{} \\
\hline
\end{tabular}




\begin{tabular}{|l|l|l|}
\hline Organization & $\begin{array}{l}\text { Pioneering: working in a solution- } \\
\text { oriented manner is paramount, } \\
\text { opportunism, start-up. }\end{array}$ & $\begin{array}{l}\text { Intuitive: short term focus, ad hoc, } \\
\text { immediate needs, impulsive }\end{array}$ \\
\hline Individual & Incorporative: infancy, unconscious. & Sensing: reflexing; moving. \\
\hline
\end{tabular}

\begin{tabular}{|c|c|c|}
\hline \multicolumn{3}{|l|}{ Wind 巽 } \\
\hline Cosmos & $\begin{array}{l}\text { Wind: penetrating, subtle nature, pure } \\
\text { and without bad intention, picture of } \\
\text { perseverance and patience, } \\
\text { communication and attention to details. }\end{array}$ & $\begin{array}{l}\text { Observing: orienting and setting small } \\
\text { steps, soft and penetrating forces, } \\
\text { represents small, stagnant steps. }\end{array}$ \\
\hline $\begin{array}{l}\text { Human } \\
\text { World }\end{array}$ & $\begin{array}{l}\text { Imagination: in-between possibilities } \\
\text { and protection, tradition, kinship. }\end{array}$ & Inherent human: human values, linking. \\
\hline Society & $\begin{array}{l}\text { Security: threatening and full of } \\
\text { mysterious powers and spirit beings, } \\
\text { which must be placated and appeased. }\end{array}$ & $\begin{array}{l}\text { Animistic: according to tradition and } \\
\text { ritual ways of group, tribal. }\end{array}$ \\
\hline Organization & $\begin{array}{l}\text { Intrapreneurial: Patras Familias, family } \\
\text { culture, nestor. }\end{array}$ & Coaching: traditional, continuity. \\
\hline Individual & $\begin{array}{l}\text { Impulsive: early childhood, islands of } \\
\text { consciousness, connections. }\end{array}$ & Exploring: impulses, perceptions. \\
\hline
\end{tabular}

\begin{tabular}{|c|c|c|}
\hline \multicolumn{3}{|l|}{ Fire 離 } \\
\hline Cosmos & $\begin{array}{l}\text { Fire: growth, light, looking for altitude } \\
\text { tied to the source, dependence, } \\
\text { attachment and loosening, insight, } \\
\text { seeing the truth. }\end{array}$ & $\begin{array}{l}\text { Thinking: thinking has a beginning and } \\
\text { an end, visible in the image of burning } \\
\text { wood; thoughts, words, ideas and } \\
\text { information in response to wishes or } \\
\text { motivations and impulses; not an end in } \\
\text { itself, but wants to lead to something, } \\
\text { like dialogue. }\end{array}$ \\
\hline $\begin{array}{l}\text { Human } \\
\text { World }\end{array}$ & $\begin{array}{l}\text { Conviction: identity, reference } \\
\text { frameworks. }\end{array}$ & $\begin{array}{l}\text { Meaning: intrinsic human values that } \\
\text { feed the free will of people, choices of } \\
\text { people, ethical or unethical, motivation, } \\
\text { meaningful connections. }\end{array}$ \\
\hline Society & $\begin{array}{l}\text { Power: like a jungle where the tough } \\
\text { and strong prevail, the weak serve, } \\
\text { nature is an adversary to be conquered. }\end{array}$ & $\begin{array}{l}\text { Egocentric: assessing self for } \\
\text { dominance, conquest, and power, } \\
\text { exploitive. }\end{array}$ \\
\hline Organization & $\begin{array}{l}\text { Business managing: I-focused, } \\
\text { hierarchy }\end{array}$ & $\begin{array}{l}\text { Prestigious: authoritarian, profiling } \\
\text { yourself, supervisor. }\end{array}$ \\
\hline Individual & $\begin{array}{l}\text { Sovereign: middle childhood, will, } \\
\text { purpose, ego-complex, imperial. }\end{array}$ & $\begin{array}{l}\text { Self-sufficiency: (inter)action, own } \\
\text { needs, selfish, caring physical } \\
\text { appearance, self-interest. }\end{array}$ \\
\hline
\end{tabular}

\begin{tabular}{|l|l|l|}
\hline Mountain & 艮 \\
\hline Cosmos & $\begin{array}{l}\text { Mountain: interprets the principle of } \\
\text { stability, stands for rest, meditation, sets } \\
\text { boundaries, makes things concrete and } \\
\text { tangible. }\end{array}$ & $\begin{array}{l}\text { Body: a certain shape, you cannot } \\
\text { change it and you must accept it as it is, } \\
\text { the motivation is to stay still, at rest, } \\
\text { forces are released to reflect on the } \\
\text { process. }\end{array}$ \\
\hline $\begin{array}{l}\text { Human } \\
\text { World }\end{array}$ & $\begin{array}{l}\text { Regulation: combinations, memes, } \\
\text { conformity. }\end{array}$ & $\begin{array}{l}\text { Re)production: instrumental values, } \\
\text { moral rules and norms. }\end{array}$ \\
\hline
\end{tabular}




\begin{tabular}{|l|l|l|}
\hline Society & $\begin{array}{l}\text { Order: controlled by a higher power } \\
\text { that punishes evil and eventually } \\
\text { rewards good works and righteous } \\
\text { living. }\end{array}$ & $\begin{array}{l}\text { Absolutistic: obediently as higher } \\
\text { authority and rules direct, conforming, } \\
\text { guilt. }\end{array}$ \\
\hline Organization & Controlling: bureaucratic. & $\begin{array}{l}\text { Procedural: formal rules, profiles and } \\
\text { job descriptions. }\end{array}$ \\
\hline Individual & $\begin{array}{l}\text { Confirmative: late childhood, } \\
\text { conscience, dualistic state of } \\
\text { consciousness. }\end{array}$ & $\begin{array}{l}\text { Restraining: social skills, mutuality, } \\
\text { control. }\end{array}$ \\
\hline
\end{tabular}

\begin{tabular}{|c|c|c|}
\hline \multicolumn{3}{|l|}{ Lake 兌 } \\
\hline Cosmos & $\begin{array}{l}\text { Lake: calm and focused on uplifting, } \\
\text { mirror image, and joy, though a } \\
\text { tendency towards depression, easy, } \\
\text { cheerful, fun, stands for the positive in } \\
\text { life, carefree and naivety. }\end{array}$ & $\begin{array}{l}\text { Feeling: experiences inner signals of the } \\
\text { senses, loose and bring out powerful } \\
\text { inner signals, creativity can be used for } \\
\text { good work. }\end{array}$ \\
\hline $\begin{array}{l}\text { Human } \\
\text { World }\end{array}$ & $\begin{array}{l}\text { Psychic maturity: learning processes, } \\
\text { thinking focused on creativity. }\end{array}$ & $\begin{array}{l}\text { Self-organisation: when under the right } \\
\text { circumstances all components of a } \\
\text { biological system are present, that } \\
\text { system will be 'automatically' formed, } \\
\text { will sustain itself and start to grow, } \\
\text { knowledge, results-oriented. }\end{array}$ \\
\hline Society & $\begin{array}{l}\text { Success: full of resources to develop } \\
\text { and opportunities to make things better } \\
\text { and bring prosperity. }\end{array}$ & $\begin{array}{l}\text { Multiplicity: pragmatically to achieve } \\
\text { results and get ahead, test options, } \\
\text { manoeuvre. }\end{array}$ \\
\hline Organization & Entrepreneurial: performance-oriented. & $\begin{array}{l}\text { Inspirational: venturous, results- } \\
\text { oriented. }\end{array}$ \\
\hline Individual & $\begin{array}{l}\text { Ingenuity: puberty/adolescence, } \\
\text { identity, ability. }\end{array}$ & $\begin{array}{l}\text { Struggling: conquering the world, ability } \\
\text { to take perspectives. }\end{array}$ \\
\hline
\end{tabular}

\begin{tabular}{|c|c|c|}
\hline \multicolumn{3}{|l|}{ Water 坎 } \\
\hline Cosmos & $\begin{array}{l}\text { Water: turbulence based on family } \\
\text { relationships, the power that lets itself } \\
\text { be guided, smooth movement, a } \\
\text { destructive force (danger, risks, } \\
\text { threats), integrates all obstacles in its } \\
\text { path; flowing with the water can } \\
\text { overcome depressions. }\end{array}$ & $\begin{array}{l}\text { Soul: like the river also the soul - } \\
\text { metaphorically, must flow from the well } \\
\text { in the mountain to the sea, then be } \\
\text { transformed, die, turn into clouds, and } \\
\text { eventually be reincarnated as rain in the } \\
\text { mountains. }\end{array}$ \\
\hline $\begin{array}{l}\text { Human } \\
\text { World }\end{array}$ & $\begin{array}{l}\text { Social maturity: community values, } \\
\text { benevolence. }\end{array}$ & $\begin{array}{l}\text { Growth: connectivity, commons, } \\
\text { participation. }\end{array}$ \\
\hline Society & $\begin{array}{l}\text { Community: the habitat wherein } \\
\text { humanity can find love and purposes } \\
\text { through affiliation and sharing. }\end{array}$ & $\begin{array}{l}\text { Relativistic: respond to human needs, } \\
\text { affinitive, situational, consensual, fluid. }\end{array}$ \\
\hline Organization & Collaborating: people manager. & $\begin{array}{l}\text { Engaging: consensus in decision- } \\
\text { making, connecting, deploying teams. }\end{array}$ \\
\hline Individual & $\begin{array}{l}\text { Responsibility: young adulthood, } \\
\text { interpersonal responsibility. }\end{array}$ & $\begin{array}{l}\text { Inquiring: embeddedness in mutuality, } \\
\text { mutual reciprocity, possibility to enter } \\
\text { into (loving) relationships. }\end{array}$ \\
\hline
\end{tabular}




\begin{tabular}{|l|l|l|}
\hline \multicolumn{2}{|l|}{ Thunder 震 } & \multicolumn{2}{|l|}{$\begin{array}{l}\text { Thunder: intense action, delivering one- } \\
\text { off creativity at full power, creating the } \\
\text { big lines, the rough image, lightning. }\end{array}$} & $\begin{array}{l}\text { Spirit: holy spirit, only achieved in the } \\
\text { awake state, experience first awe and } \\
\text { fear and then laugh. }\end{array}$ \\
\hline $\begin{array}{l}\text { Human } \\
\text { World }\end{array}$ & Symbiosis: co-evolution & $\begin{array}{l}\text { Mobility: resourceful, spread wings, } \\
\text { dynamic. }\end{array}$ \\
\hline Society & $\begin{array}{l}\text { Synergy: a chaotic organism where } \\
\text { change is the norm and uncertainty an } \\
\text { acceptable state of being. }\end{array}$ & $\begin{array}{l}\text { Systemic: functional, integrative, } \\
\text { interdependent, existential flexible, } \\
\text { questioning, accepting }\end{array}$ \\
\hline Organization & $\begin{array}{l}\text { Integrating: stimulating initiatives, co- } \\
\text { creator, visionary. }\end{array}$ & $\begin{array}{l}\text { Flexibility: commitment to goals and } \\
\text { action, value oriented, people - and } \\
\text { environmentally oriented. }\end{array}$ \\
\hline Individual & $\begin{array}{l}\text { Independency: adult/mid-life, } \\
\text { institutional independency. }\end{array}$ & $\begin{array}{l}\text { Rediscovering: self-government, } \\
\text { personal autonomy, reassessing } \\
\text { professional status and make changes, } \\
\text { full of promise. }\end{array}$ \\
\hline
\end{tabular}

\begin{tabular}{|l|l|l|}
\hline Earth 坤 & \multicolumn{3}{|l|}{} \\
\hline Cosmos & $\begin{array}{l}\text { Earth: space is created to land well and } \\
\text { produce fruit, flexibility, speed, and } \\
\text { reception, the tangible, dark, heavy, } \\
\text { non-active. }\end{array}$ & $\begin{array}{l}\text { Receptive: the receptive earth wants to } \\
\text { receive the seeds and save it for the } \\
\text { future. }\end{array}$ \\
\hline $\begin{array}{l}\text { Human } \\
\text { World }\end{array}$ & $\begin{array}{l}\text { Nooism: unification, universalism, } \\
\text { collective consciousness, group } \\
\text { awareness. }\end{array}$ & $\begin{array}{l}\text { Terminal: encompassing thoughts about } \\
\text { humanity in relation to the entire } \\
\text { universe, comprehension of the parts by } \\
\text { reference to the whole, Teilhard de } \\
\text { Chardin's Omega point. }\end{array}$ \\
\hline Society & $\begin{array}{l}\text { Holism: a delicately balanced system of } \\
\text { interlocking forces in jeopardy at } \\
\text { humanity's hands, chaordic. }\end{array}$ & $\begin{array}{l}\text { Holistic: experiential, transpersonal, } \\
\text { collective consciousness collaborative, } \\
\text { interconnected. }\end{array}$ \\
\hline Organization & $\begin{array}{l}\text { External networking: the Good One, } \\
\text { generalism. }\end{array}$ & $\begin{array}{l}\text { Idealistic: harmony seeker, balanced } \\
\text { growth, attention to people and planet. }\end{array}$ \\
\hline Individual & Generativity: old age, interindividual. & $\begin{array}{l}\text { Contemplating: cross fertilization, } \\
\text { mutual social support, wisdom, } \\
\text { achieving a true balance of self and } \\
\text { other, creating a true community that } \\
\text { develops all the emerging persons within } \\
\text { it. }\end{array}$ \\
\hline
\end{tabular}

\section{CONTRASTS}

In this section we present a method to deal with contrasts that we encounter in different situations. Yin and Yang are continuously changing, and are endlessly transforming one into the other in an eternal dance of becoming. The Yin-Yang dynamic is essential to achieve harmonious balance. It describes how seemingly opposite, but complementary forces are interconnected and mutually dependent. Emphasizing one extreme over the other is what causes one to lose equilibrium. Harmony is only achieved when the two forces are in balance. This constant change operates in a cyclical pattern. There is no 
balance of Yin-Yang if there is excess or deficiency of either Yin or Yang. When there is no more separation between Yin and Yang we experience unity of Yin and Yang, which is called the Dao (道).

I draw up a general systematic methodology for achieving harmonious balances. I observe four contrasts and follow a hierarchical process where degrees of freedom are decreasing in each contrast. I start with maximum degrees of freedom in confronting inspiration of Heaven with receptiveness of Earth. This is a process that I call 'Balancing ultimate polarities' where we weigh fundamental values. Harmony is achieved by finding core values. In the next contrast, with less degrees of freedom, observing of Wind and spirit of Thunder meet. In this process of what I mention 'Cultural relativism' we develop fundamental objectives, which will lead to a vision that provides harmony. The third contrast, with minor degrees of freedom, encounters light and thinking of Fire and relationships of Water. I indicate this process as 'Reciprocal solidarism', which establishes fundamental purposes and will lead to a mission that brings harmony. The final contrast, with lowest degrees of freedom, stability of Mountain and feeling of Lake stand face to face. This process that I label 'Creative moderation' constitutes fundamental operations that will conduct a strategy that delivers harmony.

This methodology has universal application possibilities. It can be used at all levels discussed in the former section. Examples are business and country strategic planning initiatives. Also the adoption of the Sustainable Develoment Goals (SDGs) by the international community can be mentioned as an example.
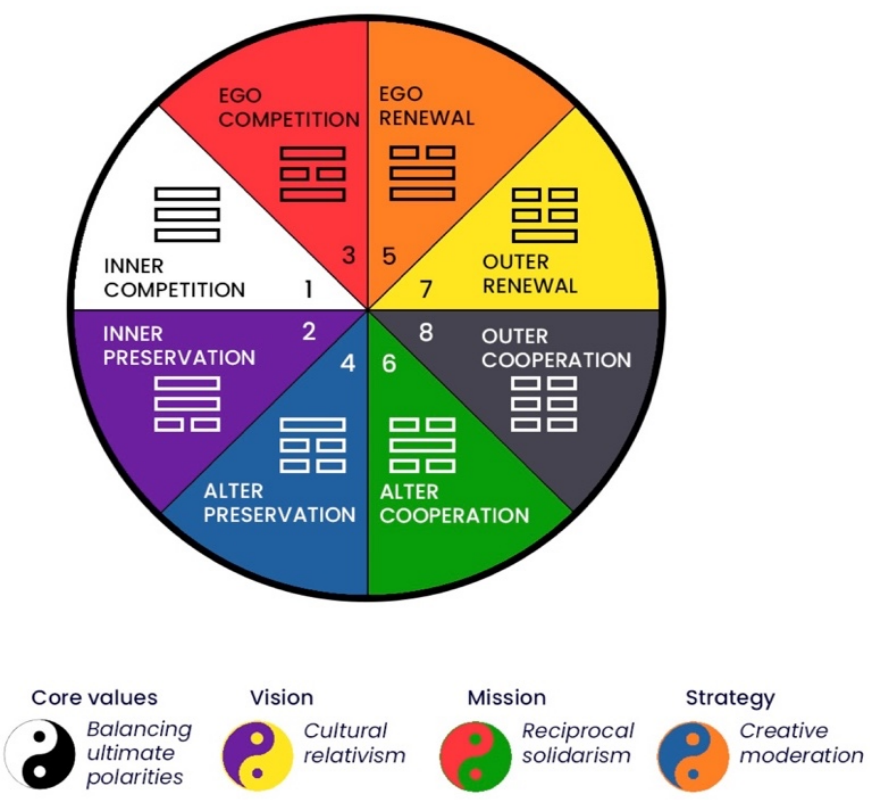

Figure 9. Contrasts between trigrams in the comparative octant model 
I demonstrate this method with an example at society level. I choose the current neoliberal system that has a number of disadvantages, accompanied by crises, of which Oudenampsen and Mellink (2019) give a nuanced picture. I will respond to the question how to improve the situation, where I rely on the approach of the platform "2local", which is a loyalty platform that supports local-2-local activities and sustainability (https://2local.io). It is tapping into banking with native L2L tokens, which are designed to rise in value as part of a cashback system. The goal is to achieve a sustainable world with prosperity for all. To get a grip on monitoring and controlling the transformation process we see the events in our society as the result of the interplay between polarities. Based on the four contrasts in the comparative octant model, see figure 9, we discuss the new approaches and possible solutions that the platform "2local" advocates to solve the problems connected to the neoliberal system and prevent new crises in the future.

At the society level, finding core values by 'balancing ultimate polarities' ensures a balance between energy that is competitively inward-oriented to survive, and energy that is cooperatively oriented outwards towards holism. It establishes a balance between current ideas and favourable visions of the future. Developing a vision by 'cultural relativism' ensures harmony between inwards oriented energy to preserve situations, guaranteeing security, and outwards oriented energy towards synergy by introducing renewals. It safeguards balancing between focusing on closed groups and opening up to innovation. Working out a mission by "reciprocal solidarism" ensures that alter-cooperative communities operating in society adequately counterbalance egocompetitive power of individuals. It provides equilibrium between self-interest and modesty. Establishing a strategy by "creative moderation" ensures that inner preservation that creates order, balances with ego-renewal that stimulates knowledge development and creativity of people. It arranges that renewals in society be introduced with care.

Core values

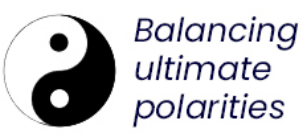

Effective transition towards sustainability and prosperity for everyone

The first contrast (1. white versus 8 . black) balances ultimate polarities by confronting inner competition with outer cooperation. In inner competition, aspirational energy is inwards directed on competition. We observe this situation currently in an entangled neoliberal world where large banks and multinationals, based on internal and competitive interests, dominate. In this world we run from crisis to crisis: climate change, depletion of natural resources, loss of biodiversity, inequality, hunger, malnutrition and poverty. The Covid-19 pandemic and the rapid global spread of the virus make this international entanglement even more clear and a transformation to a new system even more urgent. The inward-oriented competitive interests that we observe in the (neo) liberal society are contrasted with outer cooperation, where energy of cooperation is directed outwards for a favourable view of future society where sustainability and prosperity are more common. Initially, individual freedom for all was 
the old ideal of classical liberalism, which would be arranged by the free market. However, the free market, which still sets the global stage, did not regulate it. Instead, it allowed privileged individuals and companies to build wealth and realize profits, putting self-interest at the foreground. Capital is mobile, hardly hindered by government rules, and seeks ways to maximize returns. On the one hand this has fuelled greed to the powerful and on the other hand indifference to the powerless. There is hardly any attention for sustainability and prosperity for everyone.

The platform "2local" started a reassessment of our 'values' concept envisioning the kind of world we want to live in. "2local" aims to transforrm global sustainability and prosperity into accessible core values by eradicating global poverty and hunger and solving environmental and climate problems. More and more people accept the belief that things can be done differently and better and feel an urgent need to turn things around now, so that selfish interests cannot dominate the world anymore.

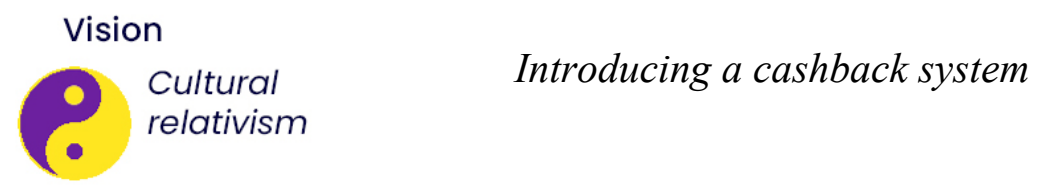

The second contrast (2. purple versus 7. yellow) confronts inner preservation with outer renewal, an activity of cultural relativism. In inner preservation, energy of cultural efforts is inward-directed to preserve the status quo, guaranteeing security. Nobility and family businesses, operating in closed circles benefited primarily of the rise of industrialism, driven by the free market system. Multinationals and large banks developed as a result. In the neo-liberal economy only a few industrialists, rich people and shareholders of big companies determine the course of events. In many exclusive forums and think tanks neoliberals met and made contacts to gain political influence, a.o. Chicago School, Mont Pèlerin Society (MPS) and pendants. Although formally the interests of all stakeholders, like employees, consumers and other involved parties must also be included in the decisions of large companies, this is hardly the case in practice. These 'closed groups' have had a lot of influence on economic policy and seek to preserve this situation. Billionaires and politicians take care of one another; they play the game together (Freeland, 2012) and perpetuate inequality in the world. The reward for capital was, and still is, higher than the reward for labour, which creates inequality (Piketty, 2014). The Credit Suisse Global Wealth Databook, Credit Suisse (2015), is a study of global household wealth. It provides detailed information on the evolution of the global distribution of wealth, both at a regional and a country level. Based on this study Oxfam (2016) points out that the richest 1\% now has as much wealth as the rest of the world combined. This inequality means that wages are lagging behind and more and more people are feeling excluded from participation in society. Still a lot of people suffer from poverty and hunger. The globalized production systems are successful in output and profitability, but causing ecological and social issues to lose. This also means that people retreat to their 'safe' environments and stand up for the interests of 
their 'own' groups. As a result both the rich and the poor shield themselves from other groups. There is hardly any attention for cooperation symbiosis, synergy and diversity.

In cultural relativism internally oriented preservation meets as its opposite renewal with outwards oriented energy. This creates respectful and truthful behaviour that can take advantage of differences. The platform "2local" works towards a society that acknowledges the cultural differences between people. If we want to replace the current preservative system, we must ensure equality between women and men, assure them of a certain basic income, reduce excessive labour and involve young people. The vision of "2local" ensures more diverse involvement, inviting a range of people to engage with each other and their local societies. This will lead to diversity and symbiosis by introducing a cashback system that will function as a light form of basic income. Consumers who have purchased local and sustainable goods and/or services from connected companies receive periodically a cashback up to a certain maximum. This makes the local and sustainable products not only more affordable for everyone but also stimulates a development towards a more sustainable world. Thresholds to participate are lower.

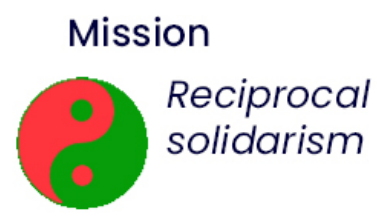

\author{
Supporting local-to-local cooperation and \\ sustainable communities
}

The third contrast (3. red versus 6. green) relates to ego competition versus alter cooperation, which is called reciprocal solidarism. In ego competition, competition is oriented towards self-interest. With the increase in international trade, multinationals and international banking accumulated more and more power. This development led to the crisis of the 1930s due to overproduction in agriculture and industry and speculation with borrowed money, in which the government did not intervene. On a global scale multinationals and large banks operate on the basis of oligopolistic competition. They do this in long international chains based on lean production methods, global sourcing, minimum stocks, no buffers, and only the short-term counts. The price developments of purchases and sales are particularly important; other aspects, such as sustainability, avoiding pollution, fairness in trade, hardly play a role. Moreover, these long international supply chains are highly vulnerable, as now evident from the Covid-19 crisis. Multinationals have too strong a power position in the economy. They swallow up promising small companies or block them from entering the market. This kills fair competition. They strategically locate where they can benefit most from the supply of materials, infrastructure, labour costs, availability of resources, legal aspects and where environmental standards are lowest. Multinationals split operating income and costs between countries, to ensure they pay little or no taxes, often facilitated by governments. Large companies are exploiting their dominant position and even putting governments under pressure. Governments do a great deal to keep these companies within their 
national borders. People choose "me first" to "survive", which has allowed populism to arise. There is hardly any attention for cooperation.

To contrast the possibility of exploiting competitive power, we need to develop interest in the other and focus on outward-oriented cooperation. This alter cooperation necessitates far-reaching cooperation and solidarity, also internationally. To change things on a global level, we must start at a local level, as various scientific and policy reports recommend. For example, Babu (2019) from the International Food Policy Research Institute (IFPRI) says: "To transform the global food system and sustainably feed the world, start at the local level." Converting the power of multinationals and banks into closer local-to-local and sustainable cooperation requires a turnaround. The mission of "2local" is to solve the aforementioned crises through a bottom-up approach that focuses on the local level. "2local" places this local concept within a global perspective. Local-to-local communities are competent to reconnect producers and consumers via trust building in short chains. They have the ability to close ecological cycles locally and build sovereign regions by own governance.

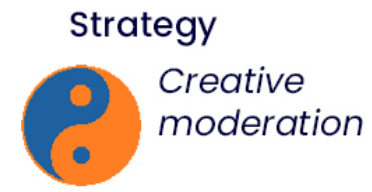

Introducing a new crypto currency system based on blockchain technology

The fourth contrast (4. blue versus 5. orange) confronts alter preservation with ego renewal, which is named creative moderation. In alter preservation, energy of cultural efforts is outward-directed to preserve the situation by using controlling mechanisms. After the Great Depression of 1930s, growing government intervention emerged because monopolies and cartels showed up and this development could lead to totalitarian states. Neo-liberal reforms also led to more attention for the public sector. A cultural shift in thinking about social security, the community and the family was established. Think of the emphasis on "norms and values", "participation society", "caring society" with the idea: more personal responsibility and less expectation from the welfare state. Market forces were introduced that combined with a controlling government would lead to individual freedom and responsibility. However, the benefits are unclear and it led to major government controls, bureaucracy and falling wages of workers. International rules were also drawn up, such as by OECD (internationally responsible entrepreneurship), ILO (decent work) and European Commission (Green Deal). Nonetheless, these rules were not made mandatory or were not enforced. Currently, the financial sector is increasingly dominating the economy. Banks are private companies that create money out of nothing because their customers make debts and they charge interests. The interest that must be paid on these debts ultimately leads to a transfer from the lowest $95 \%$ of the population to the top $5 \%$, who use it to reinvest only in their own interest, which further increases inequality. This system only can survive in an economy of growth and ensures a continuous depreciation of money. It appears that the working methods and mechanisms of banks and multinationals even lead to scandals, money laundering (e.g. libor) and green washing. Multinationals, such 
as Shell and Philips, enjoy public goodwill by talking about effective climate policy, but simultaneously they ensure that it does not happen, by taking on activities such as employing 75 lobbyists through the European Chemical Industry Council (ECIC) (Engelen, 2018). During the 2008 financial crisis governments supported banks first. The crisis was "resolved" by increasing global debt and low interest rates, which are now causing problems for pension funds in particular, and massive austerity operations with lower wages in the public sector in subsequent years. Now, in the Covid-19 crisis central banks are buying public and private debt to cut interest rates and bring greater liquidity to their already-skewed financial system. The poor and emerging markets are hit hardest. Many countries have already registered with IMF for emergency support. We conclude that rules and norms are not effective, not in business and not in the public sector. During this period the government has strongly stimulated knowledge development, however mainly driven in the direction of the prevailing market forces and large companies.

Creative moderation is a dynamic adaptive phenomenon. In opposition to inner preservation, that creates order, stands ego renewal, stimulating knowledge development and creativity of people, thus avoiding unnecessary or ineffective rules as much as possible. Creative moderation ensures that renewals are carefully introduced. The Covid-19 crisis shows that fewer rules in the hospitals during the lockdown lead to a huge explosion of creativity by the hospital staff. The strategy of "2local" is to develop and introduce new fair decentralized forms of money through cryptocurrencies that function as community coins. Crypto currencies can be issued outside the government or other agencies to benefit the people who need them. No intermediaries are needed. Worldwide over 2500 currency systems have already been developed to counteract the disadvantages of the global economic and financial system outlined above (Lietaer, 2019). By introducing crypto currencies banks can no longer exercise their monopoly position and they are no longer indispensable in society. Renewal in the business sector is to be focused on downscaling, where the local becomes the mainstream. "2local" supports local communities with a new payment system, making innovative use of blockchain technology. A distributed network with no central power maintains blockchain and guarantees openness and transparency. With relatively simple means, "2local" can use this technology to make a rigorous transition to sustainability and prosperity for everyone. A new crypto currency system, the L2L coin, ensures that consumers engage connected companies and do business at the local level. Unlike fiat money or other stable coins, which are subject to inflation, the L2L crypto currency, based on its own blockchain, will show a steady rise in value.

\section{SUMMARY}

In this paper I deduce a cosmic model from the Yi-Jing, based on the Diagram of the Supreme Polarity. This diagram is a neo-Confucian concise overview of the evolution of the dynamic and self-generating cosmos. I present an elaborated version of the Diagram, that consists of an immanent process from the void $(\mathrm{Wu}-j i)$ via the oneness (Tai-ji), the twofold (Yin and Yang), the fourfold (duograms) and the Five elements in 
combination with the trigrams $(B a-G u a)$ to reproduction and the innumerable beings, and then all the way back through a transcendent process. Between the duograms we discover a natural and a cosmic process. The foundation for differentiation in the Tai$j i$ is laid by the pattern, $l i$, and the vital energy, $q i$. The trigrams are interrelated with the production and the conquest cycle of the Five Phases.

The duograms are further discussed in the quadrant system of the cosmic ring. Regarding the pattern $l i$ and vital energy $q i$ there are similarities and differences with the model of comparative philosophy of Libbrecht. So, in the concept of Libbrecht, energy in nature is immanent and only in humans it is transcendent. In Libbrecht's concept from the primeval beginning there is bound energy and only with the introduction of the human consciousness free energy arises. As in the Reflexive Universe of Arthur Young, I think the primeval beginning started with free energy inside oriented that in a process of millions of years of immanence resulted in a phase of bound energy, where after a transcendent process arose resulting in free energy outside oriented. The form aspect (in-form-ation) generates how things take shape, which is a directional, not directed, development process with different options. I mention this directedness intentionality, with poles ego (Yang) intentionality and alter (Yin) intentionality. My interpretation of intentionality is broader than that of Libbrecht. In my view also in natural world (cosmos) intentional processes take place. These processes, however, are not induced by human (moral) interaction, as in the human world, but by Yang-Ying dynamics.

A clockwise sequence in the quadrant system present the natural cycle, Old Yang, Young Yin, Old Yin and Young Yang, as we see this e.g. in the sequence of winter, autumn, summer and spring. The spiral sequence in the quadrant system is a process sequence of the change of Yang into Yin.

The trigrams are further studied in an octant system, that I derive by adding diagonal axes to the quadrant system. These diagonal axes are based on the tension between Old Yang and Old Yin, represented by competition and cooperation and on the tension between Young Yin and Young Yang, represented by renewal and preservation. This approach leads to the new YI Ba-Gua developed by Donkers (2019). Compared to the $B a-G u a$ of $\mathrm{Fu} \mathrm{Xi}$ the trigram pairs Fire-Water and Lake-Mountain are interchanged. The spiralling sequence of the trigrams corresponds to the order of the production cycle of the Five Phases. In this sequence of trigrams we see an alternate influence of ego and alter orientation and a flow from free energy inside via bound energy towards free energy outside.

Looking at the energy and pattern in the octant model, the following stands out. The qualities of the trigrams, like change, transformation and movement originate from the power $q i$ and result in order and pattern $l i$. Trigrams therefor have two sets of qualities that exist side by side and are never separable: that what makes that a trigram is or force and that what makes how a trigram is or image. The images and forces of the trigrams are the result of the interaction of $l i$ and $q i$. In the octant system the images - or states - of the trigrams are displayed in the octants and the forces - or stages - are depicted as nested circles. When we look at the degrees of freedom of the trigrams in the sequence of the production cycle we recognize the immanent and transcendent 
process of the evolution of the cosmos. I show that this model is consistent with various modern approaches of societal studies, like Wilber's Integral Theory, Reflexive Universe, Spiral Dynamics, etc.

A core principle of Yi-Jing is that all parts of the entire cosmos belong to one organic whole. The model based on Yi-Jing can be used to analyse situations and problems at different levels: cosmos, human world, societies, organizations and individuals. I presented a brief description of the states and stages at these different levels. I developed the Human world level analogues to the Reflexive Universe of Arthur Young; the society level corresponds with Spiral Dynamics; at the organizational and individual level I used relevant literature.

Based on the four contrasts in the octant system I draw up a general systematic methodology for achieving harmonious balances. I observe four contrasts and follow a hierarchical process where degrees of freedom are decreasing in each contrast. In the Heaven-Earth contrast harmony is achieved by finding core values through an activity that I call 'Balancing ultimate polarities'. Wind-Thunder contrast will lead to a vision that provides harmony through an action that I mention 'Cultural relativism'. The FireWater contrast will lead to a mission that brings harmony through an exercise that I indicate as 'Reciprocal solidarism'. The final contrast, with lowest degrees of freedom, Mountain-Lake will conduct a strategy that delivers harmony through an operation that I consider as 'Creative moderation'. This methodology has universal application possibilities. Examples are the adoption of the Sustainable Develoment Goals (SDGs) by the international community, country and business strategic planning initiatives.

I apply the model to the current neoliberal system that has a number of disadvantages and I mention how the platform "2local" (https://2local.io/) responds to the question how to improve the situation. Contrary to current ideas of neoliberalism "2local" posits favourable perceptions of the future as core values (Balancing ultimate polarities). Against the primary focus on the short term and self-interest of the current economic and financial system, the platform "2local" considers a system that is more sustainable and prosperous for all. Opposite the few industrialists, rich people and shareholders of big companies that determine the course of events associated with increasing inequality, the vision of the platform "2local" is to introduce a cashback system for local and sustainable products, where people of all cultures profit (Cultural relativism). In front of the accumulated power of multinationals operating on the basis of oligopolistic competition, the mission of the platform "2local" supports cooperation in local communities that reconnect producers and consumers in short chains (Reciprocal solidarism). In the face of national and international rules and norms that are setup by governments to mitigate the excesses of neoliberalism, the increasing drawbacks of the international banking system and the one-sidedly driven knowledge development, the strategy of "2local" is to introduce a new crypto currency system, with L2L-coins, based on new and transparent blockchain technology, which implements the cashback system and provides a marketplace for consumers and connected companies to engage (Creative moderation). 


\section{ACKNOWLEDGMENTS}

The author thanks Antony Chang and Henk de Leeuw for various discussions about the subject of this paper, and Richard Monturo and an anonymous referee of the journal Comparative Philosophy for their valuable comments on an earlier draft of this paper.

\section{REFERENCES}

Adler, Joseph A. (2015), Reconstructing the Confucian Dao, Zhu Xi's Appropriation of Zhou Dunyi (New York: State University of New York Press).

Babu, S. (2019), To transform the global food system and feed the world sustainably, start at the local level, Blog, International Food Policy Research Institute (IFPRI), Retrieved from: <https://www.ifpri.org/blog/transform-global-food-system-andfeed-world-sustainably-start-local-level $>$

Beck, Don E. and Cowan, Chris C. (2006), Spiral Dynamics: Mastering Values, Leadership and Change (Malden: Blackwell Publishing).

Boering, Han (2010), I Tjing essenties, Inzicht in het Boek der Veranderingen [I Ching essences, Understanding the Book of Changes] (Cothen: Uitgeverij Juwelenschip).

Bor, J. and Van der Leeuw, K. (red.) (2013), 25 Eeuwen Oosterse Filosofie [25 Centuries of Eastern Philosophy] (Amsterdam: Uitgeverij Boom).

Cacioppe, R. and Edwards, M. (2005), "Seeking the holy grail of organizational development: A synthesis of integral theory, spiral dynamics, corporate transformation and action inquiry", Leadership \& Organization Development Journal 26.2: 86 -105. <https://doi.org/10.1108/01437730510582536>

Cheng, Chung-Ying (2009), "Li and $Q i$ in the Yijing: A Reconsideration of being and nonbeing in Chinese Philosophy", Journal of Chinese Philosophy, Supplement to 36: 73-100. <https://doi.org/10.1111/j.1540-6253.2009.01554.x>

Chaisson, E. J. (2005), Epic of Evolution: Seven Ages of the Cosmos (New York: Columbia University Press).

Credit Suisse (2015), "Global Wealth Databook 2015: Total net wealth at constant exchange rate (USD billion)". <http://publications.credit-suisse.com/tasks/render/ file/index.cfm?fileid=C26E3824-E868-56E0-CCA04D4BB9B9ADD5>

Donkers, Harry (2016), "Integral Dynamics, A new Integration of Wilber's Integral Theory and Spiral Dynamics", International Journal of Humanities and Social Science 6.6: 86-106.

Donkers, Harry (2019), "Yi-Jing Integral (YI), A New Natural and Cosmic Ba-Gua", Comparative Philosophy 10.2: 1-44. <https://doi.org/10.31979/2151-6014(2019). 100204>

Engelen, Ewald (2018), "Corruptie", De Groene Amsterdammer 142.41: 9.

Erikson, Erik H. (1963), Childhood and Society (2nd ed.) (New York: W. W. Norton \& Company).

Esch, Wil van (2017), Palet van Oosters en Westers denken: Tegenspraak of Samenspraak? Een Literatuuroverzicht [Palette of Eastern and Western thinking: 
Contradiction or Conversation? A Literature Review] (Soesterberg: Uitgeverij Aspekt).

Freeland, Chrystia (2012), Plutocrats - The Rise of the New Global Super-Rich and the Fall of Everyone Else (New York: Penguin Group).

Gao, Yan (2015), "Confucius and Plato on Virtue and its Implementation in Education for International Understanding: A Comparative Study", American Journal of Educational Research 3.1: 25-30. <DOI:10.12691/education-3-1-6>

Graves, Clare, W. (1970), "Levels of Existence, An Open System Theory of Values", Journal of Humanistic Psychology 10.2: 131-155.

Hamaker-Zondag, Karen M. (1989), Management I Tjing [Management I Ching] (Amstelveen: Bona Futura).

Heelas, Paul; Woodhead, Linda; Seel, Benjamin; Szerszynski, Bronislaw; and Tusting, Karin (2005), The Spiritual Revolution: Why Religion is giving way to Spirituality (Malden: Blackwell Publishing Professional).

Hon, Tze-ki (2010), "Zhou Dunyi's Philosophy of the Supreme Polarity", in John Makeham (ed.), Dao Companion to Neo-Confucian Philosophy (Dordrecht: Springer), 1-16.

IJssel, Suzette van (2008), Daar hebben humanisten het niet zo over, Over de rol van spiritualiteit in het leven en werk van humanistisch geestelijk raadslieden [Humanists are not talking about that, about the role of spirituality in the life and work of humanistic spiritual counselors] (Delft: Eubaron).

Jung, Carl (1931), "The Stages of Life", from The Structure and Dynamics of the Psyche, Volume 8, The Collected Works of Carl Jung.

Kegan, R. (1982), The evolving self (Cambridge, MA: Harvard University Press).

Keuning, D. and Eppink, D.J. (2004), Management en Organisatie [Management and organization] (Groningen: Wolters-Noordhoff).

Leary, T. (1957), Interpersonal diagnosis of personality (New York: Ronald Press).

Libbrecht, Ulrich (1995a), Geen muren rond culturen [No walls around cultures] (Leuven: Davidsfonds).

Libbrecht, Ulrich (1995b), Oosterse Filosofie, Een Inleiding [Eastern Philosophy, An Introduction] (Leuven: Davidsfonds).

Libbrecht, Ulrich, m.m.v. Heinz Kimmerle \& Els Janssens (eds.) (2016), Filosofie zonder grenzen [Philosophy without borders] (Antwerpen - Apeldoorn: Garant).

Lietaer, B. (2019), "A Financial Justice Warrior Who Fought for Freedom of Currency", Blog, retrieved from: <http://www.lietaer.com/2019/05/bernard-lietaer-a-financial justice-warrior-who-fought-for-freedom-of-currency/>

Maturana, H. R., and Varela, F. J. (1989), De boom der kennis. Hoe wij de wereld door onze eigen waarneming creëren [The tree of knowledge. How we create the world through our own perception] (Amsterdam: Uitgeverij Contact).

Mesker, Harmen (2002), "The Eight Houses, a preliminary survey", retrieved from: https://www.google.com/search?client=firefox-b-d\&q=Mesker\%2C+Harmen+\% $281999 \% 29 \% 2 \mathrm{C}+$ The + Eight + Houses $\% 2 \mathrm{C}+\mathrm{a}+$ preliminary + survey. 
Miller, S. (2006), "Reflections on the Reflexive Universe", retrieved 18 April 2020 from: $<$ https://www.academia.edu/168762/Reflections_on_the_Reflexive_Univers e?auto=download $>$

Oudenampsen, M. and Mellink, B. (2019), "Neoliberalisme is de schuld van alles. Toch?" ["Neo-liberalism is to blame for everything. However?"] (Amsterdam: De Correspondent), 28 August.

Oxfam (2016), "An Economy for the 1\%, How privilege and power in the economy drive extreme inequality and how this can be stopped", 210 Oxfam Briefing Paper, 18 January 2016. <https://oxfamilibrary.openrepository.com/bitstream/ handle/ 10546/592643/bp210-economy-one-percent-tax-havens-180116-en>

Piketty, Th. (2014), Kapitaal in de 21ste eeuw [Capital in the Twenty-First Century] (Amsterdam: De Bezige Bij).

Quinn, R. E. and Rohrbaugh, J. (1983), “A Spatial Model of Effectiveness Criteria: Towards a Competing Values Approach to Organizational Analysis", Management Science 29.3: 363-377.

Redeker, M.; De Vries, R.E.; Rouckhout, D.; Vermeren P.; and De Fruyt F. (2014), "Integrating leadership: The leadership circumplex", European Journal of Work and Organizational Psychology 23.4: 435-455. < https://doi.org/10.1080/ 1359432 X.2012.738671>

Scharmer, Otto (2009), Theory U: Leading from the Future as it Emerges (San Francisco, CA: Berett-Koehler).

Schöter, Andreas (1998), "Boolean Algebra and the Yi Jing", The Oracle: The Journal of Yijing Studies 2.7: 19-34.

Schöter, Andreas (2011), "The YiJing: metaphysics and physics", Journal of Chinese Philosophy 38.3: 412-426. <https://doi.org/10.1111/j.1540-6253.2011.01663.x>

Spier, F. (2005), "How Big History works: Energy flows and the rise and demise of Complexity", Social Evolution \& History 4.1: 87-135.

Tu, Wei-ming (1985), Confucian Thought: Selfhood as Creative Transformation, (SUNY series in philosophy) (Albany, NY: State University of New York Press).

Walls, L. D. (2009), The Passage to Cosmos, Alexander von Humboldt and the shaping of America (Chicago and London: The University of Chicago Press).

Wen, Haiming (2012), Chinese Philosophy (Cambridge: Cambridge University Press).

Wilber, Ken (2004), Een Beknopte Geschiedenis van Alles, een schitterende synthese van wetenschap en spiritualiteit [A Brief History of Everything, a wonderful synthesis of science and spirituality] (Rotterdam: Lemniscaat).

Wilhelm, Richard (2016), I Tjing, Het Boek der Veranderingen, Met een voorwoord van prof. dr. C.G. Jung. 21e druk, Eindredactie Harmen Mesker [I Ching, The Book of Changes, With a foreword by prof. dr. C.G. Jung. $21^{\text {st }}$ edition, Final editing Harmen Mesker] (Deventer: Uitgeverij Ankh Hermes bv).

Young, Arthur M. (1999), The Reflexive Universe: Evolution of Consciousness, (Revised edition) (September 15, 1999). (Anodos Foundation). 